\title{
LA PERVIVENCIA DEL FUNDUQ ANDALUSÍ EN LAS ciudades de Valencia, Murcia y SeVilla TRAS LA CONQUISTA. UN ESTUDIO A PARTIR DE LOS REPARTIMIENTOS DEL SIGLO XIII
}

\author{
Alicia Hernández Robles ${ }^{1}$ \\ Universidad de Murcia
}

Recibido: 9 de marzo de 2021

Aceptado: 24 de agosto de 2021

\begin{abstract}
Resumen
Este trabajo plantea las posibilidades de estudio que ofrecen los repartimientos para profundizar en el conocimiento de los fanādiq andalusíes, las alhóndigas castellanas y los alfondechs aragoneses. Para ello, tras abordar de forma breve el sistema de repartimiento y sus características, hemos presentado la relación existente entre los tres tipos de edificios. Con el análisis de la información encontrada sobre ellos en los repartimientos de las ciudades de Valencia, Murcia y Sevilla se ha dado respuesta a los objetivos planteados en esta investigación: identificar las alhóndigas y los alfondechs de dichas ciudades para, a través de su cuantificación, localización y características, aproximarnos a los fanādiq de al-Andalus.
\end{abstract}

\section{Palabras clave}

Funduq, alhóndiga, alfondech, al-Andalus, repartimiento

\begin{abstract}
This work raises the possibilities of study offered by the repartimientos to deepen into the knowledge of the Andalusian fanādiq, the Castilian alhóndigas, and the Aragonese alfondechs. The repartimientos information found for the cities of Valencia, Murcia, and Seville, have been deeply analyzed. The aim is to identify the alhóndigas and the alfondechs of these cities to approach to the fanadiq of alAndalus through the quantification, location and characteristics gathered. In this paper, after a brief presentation of the repartimiento system and its characteristics, we focus and develop the relationship between these three types of buildings.
\end{abstract}

\section{Keywords}

Funduq, alhóndiga, alfondech, al-Andalus, repartimiento

\section{Résumé}

Ce travail soulève les possibilités d'étude offertes par les repartimientos pour approfondir les connaissances du fanādiq andalusi, des alhóndigas castillans et des alfondechs aragonaises. Pour ce faire, après

\footnotetext{
Departamento de Arqueología, Prehistoria, Historia Antigua, Historia Medieval y Ciencias y Técnicas Historiográficas, Universidad de Murcia, Campus de La Merced, 30001 Murcia, España. Correo electrónico: alicia.hernandez5@um.es. OrciD: https://orcid.org/0000-0001-8452-5258.
} 
avoir brièvement abordé le système de repartiminento et ses caractéristiques, nous avons présenté la relation entre les trois types de bâtiments. Avec l'analyse des informations trouvées à leur sujet dans les repartimientos des villes de Valence, Murcie et Séville, une réponse a été donnée aux objectifs énoncés dans cette recherche: identifier les alhóndigas et les alfondechs de ces villes pour rapprocher $\mathrm{du}$ fanādiq d'al-Andalus, à travers à la quantification, la localisation et les caractéristiques recueillies.

\section{Mots-clés}

Funduq, alhóndiga, alfondech, al-Andalus, repartimiento

\section{El sistema del repartimiento y las posibilidades que ofrece en el estudio de los fanādiq, alhóndigas y alfondechs ${ }^{2}$}

La elección de Valencia, Murcia y Sevilla como estudios de caso se debe tanto a la similar cronología en la que se llevaron a cabo sus repartimientos como a su relevancia como ciudades principales de las zonas del levante, sureste y suroeste de la Península respectivamente. En el siglo XIII se produjeron conquistas feudales decisivas que redujeron el territorio andalusí al reino nazarí de Granada, y con el sistema del repartimiento se pretendió asegurar la permanencia de población en los territorios conquistados.

Tras la conquista feudal de al-Andalus se trató de establecer un nuevo sistema de relaciones sociales importado por los nuevos pobladores cristianos que conllevaría cambios generales en el parcelario de las urbes. Sin embargo, la población cristiana en los primeros años tras la conquista continuó viviendo en ciudades que mantuvieron el urbanismo islámico anterior. En ellas el proceso de reorganización fue progresivo, a pesar de las medidas promovidas por el $\mathrm{rey}^{3}$, y quedó recogido en diversos fueros y privilegios otorgados por el monarca, al mismo tiempo que se realizaron distribuciones de propiedades urbanas y rurales, recopiladas en los llamados libros del repartimiento. En estos documentos quedaron reflejadas algunas de las respuestas y soluciones adoptadas

\footnotetext{
2 Este trabajo forma parte de la tesis doctoral en marcha financiada por el Programa Predoctoral FPU del Ministerio de Ciencia, Innovación y Universidades (FPU16/00218). Este estudio se ha realizado en el marco del proyecto $\mathrm{I}+\mathrm{D}+\mathrm{i}$ Los orígenes de la presencia italiana en Murcia (siglos XII al XV) (2019-2022, cod. 20896/PI/18) de la Fundación Séneca (Agencia Regional de Ciencia y Tecnología, CARM) y del Convenio de colaboración entre el Excmo. Ayuntamiento de Murcia y la Universidad de Murcia para la investigación científica, formación, puesta en valor y difusión del Yacimiento Arqueológico de San Esteban.

3 Para saber más sobre el urbanismo feudal y los cambios y continuidades que se produjeron tras la conquista cristiana remitimos a los trabajos de A. Serra, para el caso de Valencia, A. L. Molina, J. Navarro y P. Jiménez, para Murcia y A. Collantes de Terán sobre Andalucía: SErra Defilis, Amadeo, "Nuevamente cristiana, bella y atractiva. La ciudad de Valencia entre los siglos XIII al XV”, Historia de la Ciudad. Recorrido histórico por la arquitectura y el urbanismo de Valencia, Colegio Oficial de Arquitectos de la Comunidad Valenciana, Valencia, 2000, pp. 64-75; Molina Molina, Ángel Luis, Urbanismo medieval. La Región de Murcia, Universidad de Murcia, Murcia, 1992; Jiménez Castillo, Pedro, y Navarro Palazón, Julio, "El urbanismo islámico y su transformación después de la conquista cristiana: el caso de Murcia", La ciudad medieval: de la casa al tejido urbano, Jean Passini (coord.), Universidad de Castilla-La Mancha, Toledo, 2001, pp. 71-130; y Collantes de Terán SÁnchez, Antonio, "De la Ciudad Andalusí a la Castellana: el espacio urbano en la Andalucía Bajomedieval", Boletín de la Real academia Sevillana de Buenas Letras: Minervae Baeticae, 37 (2009), pp. 163-192.
} 
en la ocupación, construcción y mantenimiento de los espacios conquistados. Entre los primeros pasos para cristianizar la ciudad encontramos la conversión de mezquitas en catedral y parroquias. A pesar de estas medidas iniciales, tuvieron que pasar varias décadas para que en las ciudades feudales se implantara totalmente un sistema de gobierno municipal, que desarrollara su propia gestión de las instituciones de forma autónoma, en las que las disposiciones del rey pasaran de marcar la iniciativa en la reurbanización a ser el marco legal de la administración municipal.

El repartimiento fue uno de los sistemas de repoblación utilizado tras la conquista de las ciudades de al-Andalus. Una comisión nombrada por el rey lo llevaba a cabo: efectuaba la partición y posteriormente la entrega de lotes de tierras o propiedades o donaciones individuales que más tarde eran aprobadas por el monarca. Por cada donación particular se realizaba un documento, además de quedar todos registrados de forma abreviada en los denominados libros de repartimiento. Sin embargo, no conservamos la totalidad de los registros generados durante estos procesos y debemos ser conscientes de ello cuando hacemos este tipo de estudio. Del mismo modo que se debe evitar caer en una simplificación de estos procesos, pues tuvieron distinto alcance y en ellos las acciones ejecutadas a nivel local darían lugar a distintas decisiones y soluciones ${ }^{4}$.

Con el repartimiento, el rey concedía las propiedades de los territorios conquistados entre quienes habían participado en la conquista; es decir, se producía la distribución de un botín territorial ${ }^{5}$. Dicha adjudicación se ejecutó siguiendo los principios que Laliena ha denominado "de regularidad" y "de homología". Ambos se basan en la atribución de propiedades según pautas uniformes, constituyendo lotes homogéneos en función de la jerarquía social de quien los recibía ${ }^{6}$, y en el reparto según las características jurídicas y sociales de los individuos ${ }^{7}$. Así, los bienes que poseían las autoridades islámicas pasaban a manos del rey, las mezquitas se concedían a las iglesias, y los bienes habices, las donaciones pías o waqf de la comunidad musulmana, se atribuían al monarca o a las iglesias. Del mismo modo los nobles cristianos recibían las propiedades de las élites musulmanas y las tierras y casas del campesinado andalusí se distribuyeron entre los campesinos cristianos ${ }^{8}$. Esta diversa atribución de las posesiones islámicas resulta de gran interés para los edificios objeto de estudio del presente artículo, pues tener en cuenta la propiedad de los fanādiq andalusíes permite entender la asignación

\footnotetext{
4 Laliena Corbera, Carlos, "Repartos de tierras en el transcurso de la conquista feudal del valle del Ebro (1080-1160)", Repartiments medievals a la Corona d'Aragó (segles XII-XIII), Enric Guinot y Josep Torró (eds.), Universidad de Valencia, Valencia, 2007, p. 36.

5 Guinot, Enric y TorRó, Josep, "Introducció: Retorn als repartiments", Repartiments medievals a la Corona d'Aragó (segles XII-XIII), Repartiments medievals a la Corona d'Aragó (segles XII-XIII), Enric Guinot y Josep Torró (eds.), Universidad de Valencia, Valencia, 2007, p. 11.

6 Véase el estudio detallado de la jerarquía social de los individuos que recibieron las donaciones del repartimiento de Valencia: Guinot, Enric, "El repartiment feudal de l'horta de València al segle XIII: jerarquització social i reordenació del paisatge rural", Repartiments medievals a la Corona d'Aragó (segles XII-XIII), Enric Guinot y Josep Torró (eds.), Universidad de Valencia, Valencia, 2007, pp. 115-200.

7 Laliena Corbera, Carlos, "Repartos de tierras en el transcurso de...", pp. 19-22.

8 Ibidem, pp. 22-23.
} 
de alhóndigas y alfondech a pobladores de distinto rango. La construcción de fanādiq (pl. de $f u n d u q$ ) podía estar promovida bien por los gobernantes andalusíes, por la iniciativa privada o bien constituirse como legados píos ${ }^{9}$. En consecuencia, las alhóndigas y los alfondechs pasaron a manos de propietarios de distinta condición social como el rey, eclesiásticos, pobladores que desempeñaron cargos públicos $u$ otros de los que no conocemos su ocupación.

Los repartimientos objeto de este estudio se produjeron en distintos momentos: el de la ciudad de Valencia tuvo lugar entre los años 1236 y 1244; el de Murcia fue llevado a cabo por Alfonso X entre los años 1266 y 1273; y el de Sevilla se realizó en 1253. De este último caso debemos señalar que las dos versiones con las que se cuenta, editadas por González ${ }^{10}$, destacan por la asignación de bienes rurales, puesto que no se conservó la parte concreta relativa a la distribución de la ciudad de Sevilla ${ }^{11}$. Sin embargo, aunque no hayan llegado hasta nosotros esos asientos del repartimiento, el estudio elaborado por González ha permitido recopilar una serie de alhóndigas identificadas en Sevilla.

A pesar de los cambios resultado del repartimiento y la repoblación a lo largo del siglo XIII, como las características de los habitantes o la administración de los espacios urbanos, podemos hablar de un mantenimiento de las funciones económicas de época islámica en los siglos posteriores. Ladero Quesada afirma que no fue hasta el siglo XV cuando se dio una renovación e inversión en el parcelario ${ }^{12}$. Molina Molina ha planteado en este sentido la idea de "inversión del sistema de valores" tras la conquista cristiana", al mismo tiempo que pervivieron las ubicaciones precedentes tanto de espacios abiertos como cerrados destinados a actividades económicas (calles, plazas, talleres, tiendas, alcaicerías, alhóndigas, etc. $)^{14}$. En definitiva, se puede observar que tras la conquista feudal se produjo la apropiación y asimilación de la ciudad andalusí. Esto tuvo como consecuencia que los inmuebles preexistentes ofrecieran nuevos servicios o bien mantuvieran características similares a las de época andalusí.

Desde hace unos años venimos trabajando en el estudio de la materialidad de los fanādiq en al-Andalus y, dada la brevedad de las noticias sobre ellos en las fuentes árabes, en realizar la cuantificación de las alhóndigas, en los repartimientos castellanos, y de los alfondechs, en los aragoneses, pues proporcionan información sobre los fanādiq

\footnotetext{
9 Constable, Olivia Remie, Housing the Stranger in the Mediterranean World, Cambridge University Press, Cambridge, 2003, pp. 81-83.

10 Gonzélez, Julio, Repartimiento de Sevilla (I), Consejo Superior de Investigaciones Científicas, Madrid, 1951 y GonzÁlez, Julio, Repartimiento de Sevilla (II), Consejo Superior de Investigaciones Científicas, Madrid, 1951.

11 Gonzélez Jiménez, Manuel, "Repartimientos andaluces del siglo XIII, perspectiva de conjunto y problemas", Historia. Instituciones. Documentos, 14 (1987), p. 108.

12 Ladero Quesada, Miguel Ángel, "Las ciudades de Andalucía occidental en la Baja Edad Media. Sociedad, morfología y funciones urbanas”, En la España Medieval, 10 (1987), p. 99.

13 Molina Molina, Ángel Luis, Urbanismo medieval..., pp. 105-106.

14 Ibidem, pp. 47, 52-53.
} 
andalusíes ${ }^{15}$ que estuvieron en uso en la Península antes de la conquista. Proponemos que las alhóndigas y los alfondechs, como evolución del funduq andalusí, continuaron y adaptaron la funcionalidad de estas construcciones islámicas en el contexto de las ciudades cristianas. En los repartimientos encontramos denominadas a las alhóndigas y los alfondechs como alfundicum, alfondicum, alfondica o alfundicho entre otros. El origen de estos términos podemos encontrarlos en una combinación entre el latín fundicum y el árabe funduq, o al-funduq, por el uso en árabe del artículo determinado al seguido de la palabra a la que determina.

Teniendo en cuenta estos aspectos, los objetivos del presente artículo son: en primer lugar, identificar la presencia de alhóndigas y alfondechs en los libros del repartimiento de las ciudades de Valencia, Murcia y Sevilla dada su relación con los fanādiq existentes en las urbes en el momento anterior a la conquista. En segundo lugar, cuantificar, localizar y caracterizar los fanādiq andalusíes que fueron concedidos en esos repartimientos.

Para ello hemos contabilizado las alhóndigas y alfondechs que aparecen mencionados en los repartimientos y hemos elaborado tablas con la información recopilada. En ellas hemos reflejado el término con el que son referidos los edificios, quién fue su propietario antes y después de la conquista y otras características como su emplazamiento en la ciudad o los inmuebles junto a los que se ubicaban. A partir de esta información hemos planteado su localización en el parcelario de Valencia, Murcia y Sevilla; hemos analizado las características de sus poseedores y las actividades o usos que pudieron desarrollarse en su interior; tratando de identificar cambios y continuidades en su utilización.

\section{La relación entre el funduq andalusí, las alhóndigas castellanas y los alfondechs valencianos}

Más allá de una mera cuestión de traducción y transcripción de términos del latín fundicum o del árabe funduq ${ }^{16}$, al castellano alhóndiga o al catalán alfondech, debemos tener en cuenta las similitudes y diferencias entre estos edificios antes de valorar la información recopilada de los libros del repartimiento. Al hablar de fanādiq, alhóndigas o alfondechs, nos referimos a construcciones de planta rectangular o cuadrada, generalmente de grandes dimensiones, que pudieron tener una o dos plantas en altura, y cuyas estancias se encontraban repartidas alrededor de un patio central como espa-

\footnotetext{
15 Por funduq entendemos el edificio destinado al alojamiento de comerciantes y viajeros, almacenamiento de mercancías y comercio al por mayor. Estos espacios de habitación, almacén y cuadras configuraban construcciones de grandes dimensiones y planta rectangular o cuadrada en torno a un patio central. Constable, Olivia Remie, Housing the Stranger..., pp. 88-100.

16 Para Constable los términos alhóndiga en Castilla y fondech o alfondech en el territorio de la Corona de Aragón indican que los términos fueron adoptados del árabe funduq, dado el contexto andalusí de la península Ibérica, en vez de provenir de otros términos como el latín fundicum o el italiano fondaco. Constable, Olivia Remie, Housing the Stranger..., p. 167.
} 
cio distribuidor del edificio ${ }^{17}$. Pese a que estos inmuebles parecen seguir una misma tipología arquitectónica, aceptamos lo propuesto por Constable ${ }^{18}$, lo que los diferencia fue su funcionamiento interno dependiendo del contexto geográfico y cronológico en el que se ubicaron. Los fanādiq se encontrarían en territorio islámico, como al-Andalus y otras zonas del Mediterráneo ${ }^{19}$, mientras que la presencia de alhóndigas y alfondechs en las ciudades feudales es considerada como la pervivencia y evolución de los fanādiq andalusíes ${ }^{20}$. Los términos funduq, alhóndiga y alfondech representan cosas distintas, pero proponemos que pueden ser entendidos como sinónimos en la documentación relativa a la conquista por aparecer utilizados indistintamente ${ }^{21}$.

En cuanto a las diferencias en su funcionamiento, en las alhóndigas fueron predominando las actividades de venta, almacenamiento y recaudación de impuestos o tasas sobre determinados productos, con un progresivo abandono de su uso como hospedería, con la que destacaron los alfondechs ${ }^{22}$. Los fanādiq, sin embargo, aunaron ambas características, la de alojamiento y la relacionada con el almacenamiento y comercio de mercancías, generalmente de venta al por mayor. También pudieron ser utilizados por grupos de artesanos como espacios de trabajo ${ }^{23}$. En esta transferencia y adaptación del funduq islámico al contexto cristiano en la península Ibérica ${ }^{24}$, jugó un papel muy importante tanto el desarrollo de la sociedad feudal en la Península, como los cambios en la estructura comercial del Mediterráneo medieval a partir del siglo XII. En este contexto se entiende la aparición de otra variante de estos edificios, los fondachi (pl. de fondaco), una nueva institución que surgió para alojar a grupos de comerciantes europeos, principalmente italianos, en ciudades islámicas del Mediterráneo y cuya presencia acabó extendiéndose también a territorios cristianos ${ }^{25}$. Para Constable, la aparición del fondaco es la prueba del grado de adaptación de una de las instituciones fiscales islámicas, el funduq, en beneficio del sistema de administración feudal al que la incorporaron ${ }^{26}$.

\footnotetext{
17 Torres Balbás, Leopoldo, "Las alhóndigas hispano-musulmanas y el corral del carbón de Granada", Al-Andalus, 11 (1946), pp. 446-480; Chalmeta Gendrón, Pedro, El «señor del zoco» en España: Edades Media y Moderna: contribución al estudio de la historia del mercado, Instituto Hispano-Árabe de Cultura, Madrid, 1973, pp. 142-143; y Constable, Olivia Remie, Housing the Stranger..., pp. 88-100.

18 Constable, Olivia Remie, Housing the Stranger..., pp. 164-165.

19 Torres Balbás, Leopoldo, "Las alhóndigas hispano-musulmanas...”; Chalmeta Gendrón, Pedro, El «señor del zoco»..., pp. 137-139.

20 Sobre la evolución del funduq a la alhóndiga un trabajo reciente ha estudiado su desarrollo en territorio granadino: JiMÉnez RoLDÁn, María del Carmen, "Del funduq a la alhóndiga: un espacio entre el emirato nazarí y el reino de Granada (s. XV-XVI)", al-Qantara, 40-2 (2019), pp. 315-354.

21 Ha sido habitual el empleo de estos términos como sinónimos por la historiografía. Sin embargo, consideramos que es erróneo y que simplifica en exceso la relación entre estas construcciones. Si bien es cierto que los tres mantuvieron unas características comunes a lo largo del tiempo, como son la tipología estructural del edificio, su vinculación con el almacenamiento de productos y las transacciones comerciales.

22 Torres Balbás, Leopoldo, "Las alhóndigas hispano-musulmanas...”, p. 451.

23 Chalmeta Gendrón, Pedro, El zoco medieval. Contribución al estudio de la historia del mercado. Fundación Ibn Tufayl de Estudios Árabes, Almería, 2010, pp. 302-304.

24 Constable, Olivia Remie, Housing the Stranger..., pp. 158-169.

25 Ibidem, pp. 107-111; JimÉnEz RoldÁN, María del Carmen, "Del funduq a la alhóndiga...," pp. 326-328.

26 Constable, Olivia Remie, Housing the Stranger..., p. 161.
} 


\section{Los alfondechs de la ciudad de Valencia}

En los asientos del repartimiento de Valencia ${ }^{27}$ se han cuantificado veintiuno fanädiq en el interior de la medina, tres en los arrabales occidentales y siete de los que se desconoce su ubicación, pues la información de algunos de ellos se limita al beneficiario al que fue concedido (Tabla 1). Se debe tener en cuenta que estas cifras son el resultado de la recopilación de las menciones de alfondech en el repartimiento ${ }^{28}$. Así pues, se señalarán también aquellos casos que hemos cuantificado, pero en los que la parca información que proporciona el repartimiento no permite confirmar o descartar que se trate de referencias a un mismo edificio o a inmuebles distintos en lugares próximos.

El emplazamiento de los alfondechs en el interior de la medina puede conocerse con mayor precisión por las catorce zonas o barrios en los que se distribuyó Valencia en función de la procedencia de los pobladores (Figura 1): Barcelona, Lérida, Tortosa, Montblanch, Villafranca, Tarragona, La Rápita, Montpellier, Daroca, Teruel, Calatayud, Zaragoza, Tarazona, y una zona de transición entre Daroca y Teruel. Años después la ciudad quedaría dividida por parroquias o collaciones ${ }^{29}$. Estas menciones se complementan con las alusiones a iglesias, puertas de la ciudad y baños, ofreciendo una ubicación más o menos aproximada de la mayoría de alfondechs identificados en la documentación. Así localizamos tres de ellos en el entorno de la actual plaza de la Reina y la catedral, área que formaba parte del barrio de Zaragoza. Ocho en el barrio de Teruel, entre la puerta del Puente (bāb al-Qantara) y la de la Culebra (bāb al-Hanaš) y que contaba con la iglesia de San Nicolás. Dos de estos alfondechs estaban en las inmediaciones de la iglesia de Santa Catalina, en concreto el que perteneció a Jucef Alharrat se emplazaba en rahbat al-Qādī, literalmente la plaza del juez o el alcalde, donde residían las familias de la élite de Valencia ${ }^{30}$. Los otros seis del barrio de Teruel estarían próximos bien al "baño Abinegama" o al "baño Barbo". En el barrio de Montpellier, que ocupaba la zona entre la plaza de la Figuera y la Carnicería, en la actual plaza Redonda, había otros tres. Dos estaban cerca de la iglesia de San Martín y uno frente a la desaparecida iglesia de Santa Tecla, en la actual calle del Mar. Localizamos otros dos en el barrio de Montblanch, junto a la catedral. Sin embargo, los escasos datos en uno de los asientos del repartimiento no permiten descartar que en realidad hubiera un solo alfondech en

\footnotetext{
27 Para profundizar en los aspectos conocidos del urbanismo de Valencia en época andalusí remitimos a: BARCeló Torres, Carmen, "Valencia islámica: paisaje y espacio urbano", Historia de la Ciudad. Recorrido histórico por la arquitectura y el urbanismo de Valencia, Colegio Oficial de Arquitectos de la Comunidad Valenciana, Valencia, 2000, pp. 39-49.

28 En el vocabulario de la edición del repartimiento se define alfondech o alfundicum como el edificio que podría servir a la vez de almacén y hospedería de viajeros y se menciona el término alhóndiga como sinónimo. Cabanes Pecourt, María Desamparados y Ferrer Navarro, Ramón, Libre del Repartiment del Regne de València, Anubar Ediciones, Valencia, t. I, 1979, p. 291.

29 Cabanes Pecourt, María Desamparados, El "repartiment" de la ciudad de Valencia, Anubar Ediciones, Zaragoza, 1977, pp. 12-13.

30 Barceló Torres, Carmen, "Valencia islámica: paisaje...", p. 49; BArceló Torres, Carmen, "Clave árabe para el Repartiment de Valencia", Saitabi: revista de la Facultat de Geografia i Història, 66 (2016), pp. 21 y 23 .
} 
dicho barrio. Otro estaría en el barrio de Daroca, al lado de la puerta del Librero, (bāb al-Warrāq). Este barrio se extendería desde dicha puerta hacia el oeste. En la zona intermedia o de transición denominada como Daroca-Teruel situamos otro, próximo a la puerta del Puente. Proponemos que el alfondec de texedors, en el barrio Templi, estuviera junto a los terrenos donados a los Caballeros de la Orden del Temple, al noreste de la ciudad, y a la puerta de Ibn Sajr, donde posteriormente se asentaron los pobladores de Montblanch. Otros dos se encontrarían en el interior de la medina, aunque no los hemos relacionado con ninguno de los barrios establecidos por los pobladores: uno en el barrio Tremp y otro contiguo a la puerta de Alcaltere.

Destacan en número los alfondechs en el barrio de Teruel. Dos de ellos se concedieron respectivamente a P. Sancii y P. Sanç, ambos antropónimos aparecen equiparados en el índice de nombres, y probablemente se corresponden con Pedro Sánchez, el notario del rey ${ }^{31}$. Pese a que en un primer momento se pueda pensar que es la referencia a un mismo alfondech, la mención de uno cerca del baño de Abinegama y otro al baño Barbo nos ha llevado a plantear que realmente fueran dos alfondechs distintos asignados a un mismo poblador. En cuanto a otro de los edificios que ubicamos en el barrio de Teruel solo se señala que "remanet ibi" "in vico que dederamus ominibus de Jaca". El estudio de Cabanes sobre la repoblación de aragoneses en Valencia permite relacionar dicho emplazamiento con la donación colectiva realizada a cuarenta y tres hombres de Jaca, aunque, finalmente, solo ocuparon un reducido número de inmuebles en el barrio

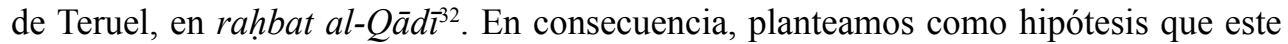
alfondech no fue asignado a ningún poblador, pudiendo haber quedado desocupado al no señalarse ni su dueño anterior ni ninguno nuevo.

Con respecto al barrio de Zaragoza, además de los asientos de los propios alfondechs, también encontramos en los de otras propiedades la descripción de su ubicación " $u b i$ sunt mezquita et alfondecs", "iuxta alfondec" o "iuxta alfondeca" 33 . En consecuencia, planteamos como hipótesis que se refieran a alguno de los tres alfondechs situados próximos a la catedral, los otorgados al arzobispo de Tarragona, Pere Albalat, o el concedido a A. de Rochafolio.

De los tres alfondechs localizados en los arrabales occidentales, solo del alfundicum de Avendonna, asignado a Bartomeu de Mora, se alude expresamente a que se hallaba extramuros de la ciudad delante de la puerta de Alhang, del árabe al-Hanaš ${ }^{34}$. Los otros dos se destinaron a los Hombres de Cervera; uno "junto al portal delante de la acequia

\footnotetext{
31 Cabanes Pecourt, María Desamparados, "Escribanos y notarios en el "Repartiment" de Valencia", Anales de la universidad de Alicante, 4-5 (1986), p. 289.

32 Cabanes Pecourt, María Desamparados, "La repoblación de los aragoneses en Valencia", Bajar al reino: relaciones sociales, económicas y comerciales entre Aragón y Valencia: siglos XIII-XV, Esteban Sarasa (coord.), Institución Fernando el Católico, Zaragoza, 2017, p. 15; CABAnes Pecourt, María Desamparados y Ferrer Navarro, Ramón, Libre del Repartiment..., t. I, 1979, pp. 34-35.

33 Cabanes Pecourt, María Desamparados y Ferrer Navarro, Ramón, Libre del Repartiment del Regne de València, Anubar Ediciones, Valencia, t. III, 1980, pp. 70 y 114.

34 Cabanes Pecourt, María Desamparados y Ferrer Navarro, Ramón, Libre del Repartiment..., t. I, p. 167.
} 
y del molino de Berenguer Revel" ${ }^{35}$. Esta ubicación se corresponde con la actual calle Carabasses e incluso se ha propuesto que pudiera tratarse de la bāb al-Hajar, la puerta de la Roca, mencionada en el repartimiento ${ }^{36}$. Es decir, que fuera una puerta abierta en la muralla del arrabal. Sin embargo, dado que no se han hallado restos arqueológicos de la cerca del arrabal ni un gran número de referencias textuales que apoyen esta hipótesis se ha planteado que se tratara de un espacio abierto entre edificios limítrofes ${ }^{37}$. El otro alfondech concedido a los Hombres de Cervera fue el alfundicho de Aben Eacob, en carraria Albenhaux, interpretado como bāb al-Hanaš, la puerta de la Culebra ${ }^{38}$.

Muchas de las propiedades del arrabal de Boatella fueron destinadas a los Hombres de Cervera ${ }^{39}$; sin duda el alfondech frente al molino de Berenguer Revel fue una de ellas. Desde la puerta de Boatella (bāb Buytāala) y atravesando el arrabal de dicho nombre, partía el camino hacia los principales centros urbanos al sur de Valencia: Denia, Alcira y Játiva ${ }^{40}$. Estas conexiones convirtieron a la puerta de Boatella en la principal de la Valencia andalusít ${ }^{41}$. Los otros dos alfondechs extramuros de la ciudad el alfundicum de Avendonna y el alfundicho de Aben Eacob estarían ubicados al norte del arrabal de Boatella, próximos a la puerta $b \bar{a} b$ al-Hanaš que conectaba la parte occidental de la medina con el arrabal.

En definitiva, podemos observar que veinte de los treinta y uno alfondechs identificados estaban próximos a iglesias, emplazadas sobre mezquitas de época andalusí, baños, hornos, caminos o puertas de la ciudad; es decir, lugares transitados propicios para que se situaran en ellos fanadiq o alfondechs.

Los siete alfondechs de los que no se aporta información precisa sobre su ubicación en Valencia fueron: el concedido a Pere Guido, médico del rey, Stephanus de Moylach y Gauçbertus de Pererio, instalado frente a las casas de los mencionados Stephanus y Gauçbertus; el alfundicum Abinexallo, asignado a Andreas Benencasa de Tortosa, delante de la casa de Roderici Didaci, notario del rey; el alfundico communi junto a los obradores de I. Anglesii y Abraym Celeda; y los otorgados a Beraldus de Cervilione, a Guillermo Porça, a Ramón de Llech y a Asensio.

\footnotetext{
35 Cabanes Pecourt, María Desamparados y Ferrer Navarro, Ramón, Libre del Repartiment..., t. I, p. 157.

36 Barceló Torres, Carmen, "Algunas notas sobre la ciudad islámica de Valencia", Homenaje a Don José María Lacarra de Miguel en su jubilación del profesorado. Estudios medievales, Anubar Ediciones, Zargoza, 1977, vol. II, p. 180.

37 Torró, Josep, y Guinot, Enric, "De la Madîna a la ciutat: les pobles del sud i la urbanització dels extramurs de València (1270-1370)", Saitabi: revista de la Facultat de Geografia i Història, 51-52 (20012002), pp. 54 y 56.

38 Cabanes Pecourt, María Desamparados y Ferrer Navarro, Ramón, Libre del Repartiment..., t. I, p. 143; Barceló Torres, Carmen, "Clave árabe para el Repartiment...", p. 16.

39 Sobre el poblamiento y el urbanismo extramuros de la ciudad de Valencia remitimos al trabajo de Torró y Guinot: TorRó, Josep, y Guinot, Enric, "De la Madîna a la ciutat...", pp. 51-103.

40 Barceló Torres, Carmen, "Valencia islámica: paisaje...", p. 44.

41 Ibidem, p. 47.
} 
Tras haber recopilado los alfondechs referidos en la documentación en función de su localización en la ciudad de Valencia, profundizaremos ahora en otro tipo de información que proporcionan los asientos del repartimiento, por un lado, sobre los propietarios musulmanes o cristianos de estos edificios, y por otro, sobre las funcionalidades o actividades que se llevaron a cabo en ellos.

\subsection{Los propietarios musulmanes y cristianos de los alfondechs de Valencia}

Del total de alfondechs identificados en Valencia solo hay mención a nueve musulmanes propietarios de fanādiq andalusíes: Alhazary, Alxarof, Jucef Alharrat, Abdella Alfaçan y Abdella Abinçally (ambos dueños de un mismo funduq), Mahomat Irazbacar, Aben Ya'qub, Abnaglop y Amet Yxiberti (también ambos propietarios de una misma construcción). Este distinto grado de detalle que ofrecen los asientos del repartimiento valenciano ha sido propuesto por Guinot como muestra de las distintas formas de asignar las propiedades por parte del rey, es decir, del contexto en el que se producía la concesión, por ejemplo, al aire libre o en la tienda real, y en función de los oficiales reales de la corte que los acompañaban ${ }^{42}$.

Los alfondechs concedidos en 1238 al arzobispo de Tarragona, Pere de Albalat, pertenecían a Alhazary y a Alxarof. Encontramos también referencias a estos alfondechs como Alxarif o Alizarif; Abinzalbo o Abinxalbo ${ }^{43}$. Barceló se ha cuestionado si las menciones en el repartimiento a "Abensalbo" (Aben Šalbūn) apuntaban al gramático valenciano Abū 'Abd Allāh Muḥammad b. Yaḥy. b. Xalaf b. Yaḥy. b. Xalaf, al-Anșārī, Aben Šalbūn ${ }^{44}$. Y si este Abensalbo era la misma persona que encontramos en el repartimiento como "Abisalbon", "Abinsalbo" o "Abenxalbo". Por la similitud de estas transcripciones con las de "Abinzalbo" o "Avinxalbo" que aparecen relacionadas con el alfondech de Alxarof otorgado al arzobispo de Tarragona, planteamos la hipótesis de que esta propiedad también pudo pertenecer al gramático Aben Šalbūn.

En cuanto a los poseedores cristianos a los que se cedieron estos inmuebles remitimos a la tabla de alfondechs de Valencia (Tabla 1). Mencionaremos aquí aquellos de los que se conoce su cargo para caracterizar estos edificios. Encontramos un alfondech asignado a Bartomeu de Mora, escriba, y otro a Bernat de Peralada, tabernero. Otros dos de estos nuevos propietarios fueron eclesiásticos. Se le concedieron dos a Pere Albalat, arzobispo de Tarragona, y otro a Poncio de Torrella, obispo de la iglesia de Tortosa.

Otros alfondechs quedaron en manos de hombres del entorno del rey. Uno fue cedido a Pedro Sánchez, notario del rey; otro a Carroç, señor de Rebollet; un tercero a Pere

\footnotetext{
42 Guinot, Enric, “El repartiment feudal de l'horta...", p. 166.

43 Martí Oltra, Javier, y Burriel Alberich Josep, "Comerciar en tierra extraña. La alhóndiga musulmana de la calle Corretgeria de Valencia", Historia de la ciudad V. Tradición y progreso, Colegio Oficial de Arquitectos de la Comunidad Valenciana, Colegio Territorial de Arquitectos de Valencia, Valencia, 2008 , p. 49.

44 Barceló Torres, Carmen, “Clave árabe para el Repartiment...”, pp. 21-22.
} 
Guido, médico del rey, y un cuarto a Ramón de Llech, equiparado en el índice onomástico del repartimiento con R. De Luch o Lluch, al que el rey atribuyó de forma vitalicia el cargo de almudaçafie.

En cuanto al alfondech concedido a Ramón de Llech o de Lluch, planteamos que la mención a ese edificio en 1240 se refiera a la "almudalafiam sive pensum de Valentia" otorgada en 1237 al noble Ramón De Luch como compensación ${ }^{45}$. Aunque no podemos descartar que se le asignaran dos alfondechs, uno como almudalafia y otro como alfondech; o que se trate de dos personas distintas, quedando para una la almudalafia y para la otra un alfondech de la ciudad.

Por "almudalafia" entendemos el lugar e institución donde ejercía sus funciones el mostassaf o almotacén. No debe ser confundida con el "almudí" o "almodí", el espacio destinado al almacén y comercio del trigo u otros cereales ${ }^{46}$. Debemos señalar que por la concesión de la almudalafia con el peso de Valencia al noble zaragozano Ramón de Lluch en 1237, se convirtió en el primer mostassaf ${ }^{47}$ tanto de la ciudad de Valencia como de la Corona de Aragón, ante la ausencia de este cargo en otras localidades ${ }^{48}$. El cometido de almudaçafie le fue concedido de forma vitalicia, sin embargo, por un privilegio en 1239, Jaime I fijó el carácter anual del oficio del mostassaf tras la muerte de Ramón de Lluch ${ }^{49}$.

El establecimiento del mostassaf y la mostassaferia en los primeros años tras la conquista, como elemento fundamental de la administración del gobierno municipal, guarda gran relación con la presencia y la actividad de los alfondechs. El mostassaf en territorio aragonés y el almotacén en el castellano controlaba el mercado, los pesos y medidas, las transacciones comerciales, la política de abastecimiento y precios o los fraudes y engaños, entre otras cuestiones ${ }^{50}$. Esta regulación de la vida pública con normativas morales y económicas se recopilaban en tratados o manuales de mercado, como ordenanzas municipales o los libros del mostassaf. Sin embargo, más allá de la relación económica y comercial de ambas instituciones, podemos determinar que ambas siguieron un desarrollo similar, pues se remontan a su precedente andalusí respectivamente y evolucionaron a partir de éstos: el funduq en el caso del alfondech y el muhtasib en el

\footnotetext{
45 Cabanes Pecourt, María Desamparados y Ferrer Navarro, Ramón, Libre del Repartiment del Regne de València, Anubar Ediciones, Valencia, t. II, 1979, p. 37.

46 Hinojosa Montalvo, José, Diccionario de historia medieval del Reino de Valencia, Biblioteca valenciana, Valencia, t. I, 2002, p. 195.

47 Sobre la figura del mostassaf y la mostassaferia como institución de la Corona de Aragón remitimos al reciente estudio sobre este oficio, la institución y su legislación realizado por P. J. Alcover en su tesis doctoral: Alcover Cateura, Pedro José, Els mercats alimentaris de la Corona d'Aragó a través de la documentació municipal (segles XIV-XV), Tesis doctoral inédita, Universidad de Barcelona, 2020.

48 Ibidem, p. 62.

49 ConTés, Josepa, Liber privilegiorum civitatis et regni Valencie. Jaume I (1236-1276), Universidad de Valencia, Valencia, 2001, t. I, p. 102; Cabanes Pecourt, María Desamparados, Organización autonómica del Reino..., p. 15.

50 Hinojosa Montalvo, José, Diccionario de historia medieval del Reino de Valencia, Biblioteca valenciana, Valencia, t. III, 2002, p. 191; CABAnes Pecourt, María Desamparados, Organización autonómica del Reino de Valencia, Anubar Ediciones, Zaragoza, 1978, pp. 15 y 17-18.
} 
caso del mostassaf ${ }^{51}$. Además, los tratados, ordenanzas o libros del mostassaf tienen su precedente también en los tratados de hisba andalusíes, denominados también tratados del buen gobierno del zoco, elaborados con el mismo propósito ${ }^{52}$.

En concreto, con respecto a la almudalafia de Valencia, desde la que Ramón de Lluch ejerció el oficio de almudaçafia como primer mostassaf. Proponemos que la mostassaferia en las primeras décadas tras la conquista se emplazó en el alfondech concedido a Ramón de Llech, mencionado en el repartimiento en 1240, si tomamos por válido que dicho alfondech esté relacionado con la almudalafia que le fue otorgada en 1237. Por último, sobre los propietarios cristianos de alfondechs debemos referirnos a los que el rey reservó para la Corona, a pesar de que no hay alusión expresa a ello. Sin embargo, documentos contemporáneos al repartimiento permiten arrojar más luz sobre esta cuestión.

La colección de Documentos de Jaime I es una fuente paralela al Libro del Repartimiento pues en ellos se recogen de manera extensa donaciones que en el segundo aparecen registradas de forma somera. En cuanto a los alfondechs en la ciudad de Valencia y su territorio se conservan algunos documentos que proporcionan más información sobre sus concesiones. Un ejemplo puede ser el del 15 de mayo de 1240, en el que Jaime I donó al obispo de la iglesia de Tortosa, Poncio de Torrella, el alfondech Azachaf, ubicado frente al baño de Alguazid, la casa de Mahomed Azedelli y el azucaque de los baños $^{53}$, término de origen árabe con el significado de callejón o callejón sin salida. Mientras que en el Repartimiento su registro de asiento ( $\left.\mathrm{n}^{\circ} 3546\right)$ permite emplazarlo frente al baño de Alguacir y la casa de Mahomat Atedeli, pero no hace referencia al beneficiario de la donación ${ }^{54}$.

En los Documentos de Jaime I de Aragón también encontramos información sobre la propiedad del rey de determinados alfondech de la ciudad. Por ejemplo, el 8 de abril de 1261 Jaime I permitió a doña Teresa Gil de Vidaure que la tintorería de Valencia se emplazara en el alcázar. El registro informa que su ubicación anterior fue en el alfundico del rey (alfundico nostro), cerca de la ferrería de la puerta de Roteros (prope ferrariam

\footnotetext{
51 Cabanes Pecourt, María Desamparados, Organización autonómica del Reino..., pp. 17-18 y 20.

52 Para la península Ibérica se conocen varios tratados de hisba que han sido traducidos: LÉvi-ProvenÇAL, Évariste y García GómEz, Emilio, Sevilla a comienzos del siglo XII. El tratado de Ibn 'Abdun, Biblioteca de temas sevillanos, Sevilla, 1981; AL-SAQAṬi AL-MĀLAQI, Kitāb fī àdāb al-hisba (Libro del buen gobierno del zoco), trad. Pedro Chalmeta y Federico Corriente, Fundación Ibn Tufayl de Estudios Árabes, Almería, 2014; AL-SAQAṬi AL-MĀLAQI, "Kitab fi adab al-hisba (libro del buen gobierno del zoco) de al-Saqati", trad. Pedro Chalmeta, Al-Andalus, 32 (1) (1967), pp. 125-162; 32 (2) (1967), pp. 359-397; 33 (1) (1968), pp. 143-195; 33 (2) (1968), pp. 432-433; IBN 'ABD AL-RA'ŪF, Córdoba a mediados del siglo X, ed. y trad. Pedro Chalmeta, Fundación Ibn Tufayl de Estudios Árabes, Almería, 2019; YaHYà IBN 'Umar, Ahkam al-suq, "Unas 'ordenanzas del zoco' del siglo IX. Traducción del más antiguo antecedente de los tratados andaluces de 'hisba' por un autor andaluz", trad. Emilio García Gómez, Al-Andalus, 22 (2) (1957), pp. 253-316.

53 Huici Miranda, Ambrosio, y Cabanes Pecourt, María Desamparados, Documentos de Jaime I de Aragón, vol. II (1237-1250), Editorial Anubar, Zaragoza, 1976, pp. 72-73.

54 Cabanes Pecourt, María Desamparados y Ferrer Navarro, Ramón, Libre del Repartiment...., t. III, p. 233.
} 
porte de Roteros). Ese mismo día, también dispuso que el almudín de Valencia, establecido en el alfondico del rey (in alfondico nostro) junto a la carnicería de Valencia (iuxta carniceriam Valencie), se trasladara al alcázar que dio a doña Teresa Gil de Vidaure ${ }^{55}$. De entre los alfondechs identificados en el repartimiento, el hecho de que no se nombre ningún beneficiario del alfundicum carniceriarum y la mención del "alfondico del rey" junto a la carnicería de Valencia nos lleva a proponer que ambas alusiones se refieran al mismo edificio y que fuera propiedad del rey. Además, en los asientos del repartimiento aparecen tanto la carnicería como el alfondech próximo a ella, por lo que consideramos que este no sería utilizado como carnicería, sino que se trataba de un inmueble relacionado con ella y anexo a ésta ${ }^{56}$.

Dos registros del 21 de diciembre de 1238, de la colección Documentos de Jaime I de Aragón, aportan más datos sobre esta cuestión al indicar los límites de la carnicería de Valencia que fue concedida por Jaime I a varios pobladores. Uno de sus límites se ubica "in carreria de Almudi et cum corralo ad opus scoriandi, qui si tenet cum bladeria sive almudino" 57 . Es decir, junto al corral que servía para matadero y el almacén de trigo o almudí, interpretado como un único edificio que, tal y como recoge el documento de 1261, era propiedad del rey ${ }^{58}$. En consecuencia, proponemos que el alfundico carniceriarum indicado en el repartimiento fuera este almudí con corral para matadero, localizado junto a la carnicería. Por lo tanto, este alfondech serviría tanto de matadero como de almacén de grano, hasta la construcción del almudí en el alcázar a finales del siglo XIII, junto a la parroquia de San Esteban, como quedó establecido en 1261.

La relación entre el corral y las alhóndigas castellanas fue puesta de manifiesto por González en su estudio sobre el repartimiento de Sevilla ${ }^{59}$, en el que remite a documentación de Toledo para argumentar esta relación pues, en 1166 se menciona el fondaque donde los carniceros degollaban las reses y, en 1170, el "corral que fue fonda del rey, en que agora degüellan los francos las vacas". Para este investigador los corrales podían servir para diferentes usos: vivienda, matadero, carnicería, almacén, funduq o alhóndiga. La relación del citado alfondech de Valencia como matadero y almudí, vendría a apoyar lo propuesto por González sobre los corrales y su función como pequeñas industrias con una estructura análoga a las alhóndigas y, en este caso a los alfondechs. Además,

\footnotetext{
55 Huici Miranda, Ambrosio, y Cabanes Pecourt, María Desamparados, Documentos de Jaime I de Aragón, vol. IV (1258-1262), Editorial Anubar, Zaragoza, 1982, pp. 299-300.

56 Cabanes Pecourt, María Desamparados y Ferrer Navarro, Ramón, Libre del Repartiment...., t. I, pp. 182 y 200.

57 Huici Miranda, Ambrosio, y Cabanes Pecourt, María Desamparados, Documentos de Jaime I..., vol. II, p. 52.

58 Cabanes Pecourt, María Desamparados, "Los primeros establecimientos comerciales de la Valencia cristiana: los obradores (siglo XIII)", El món urbà a la Corona d'Aragó del 1137 als decrets de Nova Planta, Salvador Claramunt Rodríguez (coord.), Universidad de Barcelona, Barcelona, 2003, vol. I, p. 282; Barceló Torres, Carmen, "Valencia islámica: paisaje...", pp. 45 y 49; Hinojosa Montalvo, José, Diccionario de historia medieval..., t. I, p. 195.

59 González, Julio, Repartimiento de Sevilla (I)..., pp. 506 y 509.
} 
el de Toledo era propiedad del rey, igual que proponemos en el caso del alfundico carniceriarum de Valencia ${ }^{60}$.

\subsection{Usos de los alfondechs de Valencia}

Cinco son los edificios que nos permiten hablar de cierta relación entre los alfondechs y la actividad que se realizaba en su interior. De dos de ellos no conocemos su ubicación en el parcelario urbano. El denominado alfondech de los tejedores, permite relacionar este inmueble con un grupo concreto de usuarios, los tejedores, que llevarían a cabo su labor en él. Esta relación permite plantear su uso polifuncional, no solo como almacén de mercancías, sino también como espacio productivo y de habitación. Mientras que la mención de un alfundico communi, nos ha llevado a interpretarlo con un carácter más polivalente, no destinado a un grupo concreto de personas ni a un producto específico. Por otro lado, el asiento de concesión a A. de Rochafolio del alfondech ubicado frente a la iglesia de Santa María informa de su utilización como alojamiento del rey: "in qui hospitabamini" ${ }^{\prime}$, confirmando así el uso como hospedería de estos inmuebles.

Las otras dos construcciones que aportan información sobre la actividad que tenía lugar en su interior son el alfundico carniceriarum y la almudalafia, cuya descripción ha sido planteada con anterioridad en relación a sus propietarios.

Otro aspecto sobre la administración de estos edificios valencianos es la cuestión relativa al pago de rentas, alquileres o parte de los beneficios obtenidos por la Corona. En dos asientos se establece de forma concreta el pago que debía realizarse por parte del poblador con fórmulas como "pro quo a vobis accepimus CCC solidos iaccenses" en el caso del alfondech condedido a P. Guidonis, S. de Moylach o G. de Pererio ${ }^{62}$; o "pro sexaginta solidis", en el caso del otorgado a Beraldus de Cervilione ${ }^{63}$. Por otra parte, también encontramos el caso contrario con el alfondech concedido a Bernat de Peralada, junto al portal alcaltere, pues se le cedió "franchum et liberum sine censu" es decir, sin tener que pagar el impuesto del censo a las rentas de la Corona.

Por último, no queremos concluir el apartado relativo a los alfondechs de Valencia sin mencionar la hipótesis de Burns en relación a estos edificios, en la que plantea que, por el hecho de que las alcaicerías también fueron inmuebles organizados en torno a un patio central, éstas pudieron quedar reflejadas en la documentación con el latín genérico alfundicum, por lo que propone que alguno de los alfondechs podría haber

\footnotetext{
${ }_{60}$ Un estudio sobre las alhóndigas y alfondechs de la península Ibérica propiedad de la Coronas de Castilla o Aragón ha sido realizado por O. R. Constable en: Constable, Olivia Remie, Housing the Stranger..., p. 169-171.

${ }_{61}$ Cabanes Pecourt, María Desamparados y Ferrer Navarro, Ramón, Libre del Repartiment...., t. I, p. 148.

62 Ibidem, p. 147.

63 Ibidem, p. 184.

${ }^{64}$ Ibidem, p. 186.
} 
sido en realidad una de las alcaicerías de Valencia ${ }^{65}$. Los datos proporcionados por el repartimiento no aportan información que permita confirmar o rechazar dicha hipótesis.

\section{Las alhóndigas de las ciudades de Murcia y Sevilla}

La información que los repartimientos de Murcia y Sevilla proporcionan sobre sus alhóndigas es mucho más limitada que en el caso valenciano. Para la primera ciudad, solo hay un asiento, en concreto de la Quinta partición de 1272, en el que se informa de dos alhóndigas relacionadas con el almacenamiento y la compra-venta de sal (Tabla 2). Sobre las alhóndigas sevillanas se han podido recopilar más ejemplos que en Murcia, aunque no han superado en número a los edificios identificados en la ciudad de Valencia. A partir del estudio elaborado por González sobre el repartimiento de Sevilla hemos cuantificado un total de doce alhóndigas (Tabla 3).

En el repartimiento de Murcia se menciona la "alfóndega de la sal que era mesón" ubicada en la collación de San Pedro (Figura 2), uno de los barrios del interior de la medina. Esta alhóndiga fue concedida a Berenguer Salamón, junto con unas casas derribadas adyacentes, después de que Alfonso $\mathrm{X}$ hubiera ordenado el traslado de la alhóndiga de la sal al arrabal de la Arrixaca, "a la alhóndiga que fue de Berenguel de Moncada, ante las casas que son de Guillem de Rocafull”"66. La alhóndiga del arrabal de la Arrixaca ya se encontraba en uso con anterioridad hasta que por orden de Alfonso $\mathrm{X}$ comenzó a ser utilizada como alhóndiga de la sal.

Navarro y Jiménez propusieron que los restos arqueológicos de una construcción hallada en la esquina de la calle Pascual con la calle Conde Valle de San Juan de Murcia, podrían relacionarse con la "alfóndega de la sal" citada en el repartimiento ${ }^{67}$. Sin embargo, Ruiz, directora de la intervención arqueológica, cuestionó dicha hipótesis dado que el solar se ubicaba en la antigua calle Frenería, en la collación de Santa María ${ }^{68}$. A pesar de la cercanía de dichas estructuras a la parroquia de San Pedro, se habrían mantenido los límites previos de las collaciones de la ciudad, por lo que la "alfóndega de la sal" de la collación de San Pedro no se correspondería con el edificio excavado en la collación de Santa María ${ }^{69}$.

\footnotetext{
65 Burns, Robert Ignatius, "Baths and Caravanserais in Crusader Valencia", Speculum, 46(3) (1971), p. 446.

66 Torres Fontes, Juan, Repartimiento de Murcia, Escuela de Estudios Medievales. Academia Alfonso X el Sabio de Murcia, Murcia, 1960, p. 244.

67 Navarro Palazón, Julio y Jiménez Castillo, Pedro, "Una nueva propuesta de investigación y gestión de yacimientos urbanos: la ciudad de Murcia", Paisajes rurales y paisajes urbanos: métodos de análisis en historia medieval, Universidad de Zaragoza, Zaragoza, 1994, p. 193.

68 Ruiz Parra, Inmaculada, "Excavaciones arqueológicas en el solar de la C/ Conde Valle de San Juan, esquina C/ Pascual de Murcia", Memorias de Arqueología (1990), 5 (1996), p. 425.

69 Varias han sido las interpretaciones tipológicas propuestas para los restos arqueológicos del edificio de la calle Pascual: un conjunto de tiendas, un funduq o alhóndiga, o una alcaicería. Sobre esta cuestión véase: HernÁNDEZ Robles, Alicia, "Comercio y alojamiento en madinat Mursiya. Estudio arqueológico de los fanādiq andalusíes en Murcia”, Arqueología y Territorio Medieval, 28 (2021), e6186.
} 
En cuanto a la localización de la alhóndiga de la sal en el arrabal del Arrixaca se ha planteado que estuviera en la calle con el mismo nombre, en la actual calle Federico Balart, antes denominada calle de la Sal, en la zona meridional del arrabal ${ }^{70}$.

Otra mención a una alhóndiga en Murcia la encontramos en el documento de 1266 en el que Jaime I otorgó unas casas a Pericó, un súbdito valenciano ${ }^{71}$. En él aparece el "alfondico del Aliatzem" como el inmueble que lindaba con las casas concedidas ${ }^{72}$. Burns transcribió el término "Aliatzem" como "almaczem" y propuso como interpretación bien que hiciera referencia a un almacén, del catalán magatzem, o bien a la propiedad del tesoro público, del árabe makhzan ${ }^{73}$.

Por lo tanto, en la ciudad de Murcia, al menos tres construcciones pueden ser interpretadas como fanādiq en época andalusí. A estas estructuras, conocidas a través de la documentación escrita, se suman las siete halladas en las últimas décadas en excavaciones arqueológicas urbanas, como la de la Plaza Belluga ${ }^{74}$ o la del conjunto arqueológico de San Esteban ${ }^{75}$. En un trabajo reciente se han analizado los siete edificios interpretados como posibles fanādiq, y se ha planteado que al menos cuatro de ellos funcionaron como funduq en época andalusíi ${ }^{76}$.

Sevilla, al igual que el resto de urbes tras la conquista, quedó dividida en collaciones por parroquias, a lo que se sumó la concesión de barrios concretos a grupos como los francos o los genoveses. A partir del siglo XIII se distinguían treinta y una zonas en Sevilla: Santa María, El Salvador, Omnium Sanctorum, San Andrés, San Bartolomé Viejo, San Bartolomé Nuevo, San Esteban, San Gil, San Ildefonso, San Isidoro, San Juan, San Julián, San Lorenzo, San Marcos, San Martín, San Miguel, San Nicolás, San Pedro, San Román, San Vicente, Santa Catalina, Santa Cruz, Santa Lucía, Santa María la Blanca, Santa María Magdalena, Santa Marina, Santiago, barrio Castellanos,

\footnotetext{
70 Ortega Pagán, Nicolás, Callejero murciano, Ayuntamiento de Murcia, Murcia, 1973, p. 111; NaVArRo Palazón, Julio y Jiménez CAstillo, Pedro, “Una nueva propuesta de investigación...”, pp. 193-194.

71 Torres Fontes, J., Documentos del siglo XIII, CODOM II, Real Academia Alfonso X el Sabio, Murcia, 1969, p. 25.

72 Pese a que el documento no proporciona ninguna referencia sobre la localización de este edificio, los arqueólogos Jiménez y Navarro plantearon la posibilidad de que la alhóndiga de la sal de la collación de San Pedro se correspondiera con el "alfondico del Aliatzem": JiménEz CAStillo, Pedro, y NAVARRo PAlazón, Julio, "El urbanismo islámico y su transformación...”, p. 90.

73 Burns, Robert Ignatius, Diplomatarium of the Crusader Kingdom of Valencia: The Registered charters of Its Conqueror Jaume I, 1257-1276 III: Documents 501-1000. Transition in Crusader Valencia: Years of Triumph, Years of War, 1264-1270, Princeton University Press, Princeton, 2001, pp. 212-213.

74 Navarro Palazón, Julio y Jiménez Castillo, Pedro, “Casas y tiendas en la Murcia andalusí. Excavación en el solar municipal de la Plaza de Belluga”, Memorias de Arqueología (1995), 10 (2002), pp. 490-532.

75 Eiroa Rodríguez, Jorge Alejandro, Haber Uriarte, María, Vallalta Martínez, Pilar, González Ballesteros, José Ángel, Hernández Robles, Alicia, Celma Martínez, Mireia, Martínez Rodríguez, Antonio Luis, Muñoz Espinosa, María Ángeles, Salas Rocamora, Sergio y Molina Campuzano, María Isabel, "El conjunto arqueológico de San Esteban: aportaciones desde la investigación interdisciplinar", XXV Jornadas de Patrimonio Cultural de la Región de Murcia, Tres Fronteras Ediciones, Murcia, 2019, pp. 41-51.

76 Hernández Robles, Alicia, "Comercio y alojamiento en madīnat Mursiya".
} 
bario Francos, barrio de Génova, y barrio de la $\mathrm{Mar}^{77}$. Se han podido cuantificar cinco alhóndigas en la collación de Santa María la Mayor, cuatro en la de San Isidoro, una en la de San Pedro, otra en la judería o collación de Santa María la Nueva y una última en el barrio de Génova (Figura 3).

Con respecto a las alhóndigas de la collación de Santa María la Mayor, en tres de ellas se señala expresamente que estaban situadas en dicha collación, mientras que, de otras dos, la ubicada en la calle Abades y la que se encontraba cerca de la puerta del Arenal, solo se mencionaban dichas referencias. Dado el emplazamiento de esos dos lugares, también formarían parte de la collación de Santa María la Mayor y así lo he reflejado en la tabla 3 que acompaña al artículo. De hecho, González ha propuesto que la alhóndiga de la calle Abades pudiera tratarse de la concedida a Lorenzo Suárez ${ }^{78}$.

En la collación de San Isidoro, al norte de la de Santa María, localizamos cinco alhóndigas al describirse las casas que estaban entre ellas. Pese a que puede interpretarse con ambigüedad la posesión de estas alhóndigas, bien como edificios cuya propiedad era compartida entre dos dueños o como independientes de cada poblador, un documento de 1264 lo deja claro al hablar por un lado de la alhóndiga de García Martínez y por otro de la de Juan Domínguez. Por este motivo hemos registrado las cinco alhóndigas como cinco inmuebles de propietarios distintos en la tabla que acompaña al artículo (Tabla 3).

Otra alhóndiga, la de la harina, propiedad del rey, se ubicaba en la collación de San Pedro, al norte de la collación de San Isidoro. En la judería, al sureste de la ciudad, se situaría otra alhóndiga, junto a las casas de Abosrayel y un baño.

Mención especial merece la alhóndiga concedida a los genoveses, puesto que realmente se les otorgó el derecho a construirla, y no un edificio preexistente ${ }^{79}$. Para este grupo Fernando III dispuso "barrium, alfondigam, furnum et balneum" aceptando la petición que el concejo de Génova le había realizado a través del embajador Nicolás Calvo. El barrio de Génova ocupaba una calle, próxima al extremo noroeste de la catedral, un tramo de la actual Avenida Constitución, que discurre entre la Plaza de San Francisco y la confluencia de las calles Alemanes y García de Vinuesa. Genoveses y pisanos habían establecido relaciones comerciales con los almohades en Sevilla, en el siglo XII, antes de la conquista castellana de la ciudad ${ }^{80}$, por lo que es muy posible que ya hubieran tenido con anterioridad un funduq en el que alojarse y comerciar. De su interés de mantener los contactos comerciales con Sevilla ahora en manos del monarca castellano, se entiende el envío por parte del concejo de Génova de una nueva embajada a la ciudad. En consecuencia, de las trece alhóndigas identificadas en la documentación sevillana, doce de ellas serían fanādiq en época andalusí.

\footnotetext{
77 Collantes de Terán Sánchez, Antonio, Sevilla en la Baja Edad Media. La ciudad y sus hombres, Ayuntamiento de Sevilla, Sevilla, 1984, pp. 180-196.

78 González, Julio, Repartimiento de Sevilla (I)..., p. 510.

79 Sobre los edificios concedidos a los genoveses véase: Torres BaLbés, Leopoldo, "Las alhóndigas hispano-musulmanas...", pp. 454-457.

80 Constable, Olivia Remie, Housing the Stranger..., p. 127; GonzÁlez, Julio, Repartimiento de Sevilla (I)..., pp. 337-340.
} 


\subsection{Los propietarios musulmanes y cristianos de las alhóndigas de Murcia y Sevilla}

De los propietarios que se han identificado en relación con las alhóndigas de la sal de Murcia, solo se conoce el cargo de Berenguer de Moncada, que fue almojarife de la ciudad de Murcia. Lo que no deja de ser interesante, pues se trataba del encargado de recaudar las rentas y derechos del rey, siendo la alhóndiga el lugar desde el que podría haber llevado a cabo esa tarea.

En el caso de Sevilla, carecemos de datos sobre la mayoría de propietarios de alhóndigas, pues solo sabemos su nombre, y tampoco aparece ninguna mención a los anteriores dueños musulmanes. En consecuencia, destacamos como poseedor al rey. Tal y como refiere la documentación, el rey era propietario de la alhóndiga de la harina en la collación de San Pedro y de la alhóndiga de la sal en la collación de Santa María la Mayor. Que el rey mantuviera para sí la posesión de estos edificios fue algo habitual. Por ejemplo, en el caso de Murcia, en el privilegio de Alfonso X al concejo de Murcia de 1267 sobre la venta de vino en la ciudad, el rey indica que los cristianos pobladores de Murcia podían vender vino a los cristianos en su casa o "ally o mejor pudiere", mientras que el monarca se reservaba la propiedad de la alhóndiga donde los moros compraban el vino: "mas retenemos pora nos alfóndiga sabuda o compren los moros vino e no en otro logar"81.

\subsection{Usos de las alhóndigas de Murcia y Sevilla}

Sobre la funcionalidad de las alhóndigas de Murcia, solo conocemos que las dos que aparecen mencionadas en el repartimiento estuvieron dedicadas al almacenamiento y la compra-venta de sal. La alhóndiga "de la sal" sería el depósito de este producto, tal y como propuso Ortega Pagán ${ }^{82}$, al que acudirían tanto comerciantes como particulares para la compra de la sal y para pagar los derechos de consumo establecidos sobre ella. En el privilegio rodado de 9 de abril de 1272, Alfonso X ordenó al almojarife que solo se vendiera sal en Murcia "en la nuestra casa de la Arrixaca o la mandamos uender" ${ }^{\prime \prime 3}$. Así se estableció el monopolio real sobre este producto a través del control de los almojarifes, así como el monopolio de la propiedad de las salinas del reino de Murcia $^{84}$. Por lo tanto, la sal, tanto de las salinas de Murcia como la que procediera de otros territorios para su venta a la ciudad, solo podría comercializarse en las alhóndigas destinadas para ello. En este caso, en la alhóndiga de la sal de la collación de San Pedro y posteriormente en la del arrabal de la Arrixaca.

\footnotetext{
81 Torres Fontes, Juan, Documentos de Alfonso X el Sabio, CODOM I, Academia Alfonso X el Sabio de Murcia, Murcia, 1963, p.46.

82 Ortega Pagán, Nicolás, Callejero murciano..., p. 111.

83 Torres Fontes, Juan, Documentos de Alfonso X..., p. 71

84 Torres Fontes, J., Documentos del siglo XIII..., p. LXI.
} 
En concreto de la alhóndiga de la sal de la collación de San Pedro se especifica que era mesón. Tal y como anticipábamos en la introducción, las alhóndigas dejaron de utilizarse como lugares de alojamiento por lo que surgieron otros edificios para este servicio, los mesones, sobre todo a partir del siglo XIII ${ }^{85}$. En consecuencia, planteamos que esta alhóndiga murciana proporcionara ambos servicios, como alojamiento y como almacén y venta de sal y de recaudación de impuestos.

En el caso de Sevilla, tres son las alhóndigas cuya información permite plantear el tipo de actividades que se llevaban a cabo en su interior. De una de ellas propiedad de Diego de Corral se refiere específicamente que tenía tiendas, por lo tanto, en ella se realizarían transacciones comerciales de forma habitual.

Por otro lado, al igual que en el caso de las alhóndigas de la sal de Murcia, las alhóndigas de la sal y la harina en Sevilla, propiedad del rey, servirían como almacén, lugar de compra-venta y pago de los impuestos por estos productos. En concreto sobre la de la harina, Alfonso X dispuso que los recueros moros que iban a Sevilla diesen en dicha alhóndiga del rey el derecho que solían dar en tiempo del miramamolín. Esta mención viene a confirmar la continuidad que planteamos entre los fanādiq andalusíes y las alhóndigas o los alfondechs en las ciudades tras la conquista feudal. En esta alhóndiga los musulmanes debían pagar por la harina como ya hacían con anterioridad en este $f u n d u q^{86}$.

\section{Conclusiones}

Los repartimientos de las ciudades de Valencia, Murcia y Sevilla informan, en mayor o menor medida, sobre unos mismos aspectos de las alhóndigas y los alfondechs: los beneficiarios cristianos a los que fueron concedidos o donados estos edificios, la ubicación o alguna de las actividades a las que fueron dedicados. Solo en el repartimiento de Valencia se han hallado menciones a los propietarios musulmanes de los fanädiq antes de la conquista. La información sobre estos en el caso del repartimiento valenciano supera con creces los datos sobre las alhóndigas en los de Murcia y Sevilla. Esto puede deberse a que la presencia de fanādiq en Valencia fuera mayor con respecto a Murcia o Sevilla. Sin embargo, debemos ser cautos con esta afirmación, puesto que la investigación en este artículo se ha centrado en el análisis de la información que proporcionan los repartimientos.

Sobre la funcionalidad de estos edificios y su desarrollo y especialización posterior, en los casos del territorio castellano, en Murcia y Sevilla, hay un mayor número de

\footnotetext{
85 Jiménez RoldÁn, María del Carmen, "Del funduq a la alhóndiga...”, pp. 332 y 336; GonZÁlez, Julio, Repartimiento de Sevilla (I)..., p. 508.

86 GonzÁlez, Julio, Repartimiento de Sevilla (I)..., p. 515; Constable, Olivia Remie, Housing the Stranger..., p. 171. Sobre la continuidad de la fiscalidad andalusí tras la conquista y su aplicación a las comunidades mudéjares remitimos al siguiente trabajo: AвBoud HAGGAR, Soha, "Precedentes andalusíes en la fiscalidad de las comunidades mudéjares”, En la España medieval, 31 (2008), pp. 475-512.
} 
alhóndigas destinadas a un producto específico (a la sal o la harina), mientras que en los asientos del repartimiento valenciano se hace mención a los alfondechs, remitiendo a su anterior propietario (alfondech de Alhazary o alfondica de Iucef Alharrat, entre otros), al nombre que tenían en la ciudad (alfonde Adarra o alfondec Açicaf) o sin hacer referencia a ninguna otra especificidad.

Esta distinción en cuanto a la especialización de los inmuebles según su presencia en territorio castellano o aragonés ha llevado a Constable a distinguir los alfondechs de las alhóndigas, proponiendo que es menos común encontrar alfondech destinados a productos concretos, dado que surgieron otro tipo de construcciones para este propósito, como los alfolíes. Para Constable los alfondechs aragoneses sirvieron como posadas para mercaderes o viajeros, mientras que este uso fue perdiéndose en el caso de las alhóndigas castellanas que se centraron en controlar el movimiento de ciertos bienes en vez del de personas ${ }^{87}$. Como argumento a favor de esta distinción en función de la utilización como hospedería, ha considerado incluso que el alojamiento era más necesario en el territorio de la Corona de Aragón que en Castilla por su tradición de comercio internacional y la mayor presencia de comerciantes en sus ciudades ${ }^{88}$.

Sobre su ubicación en el entramado urbano, la documentación proporciona algunos datos de manera más o menos concreta en función del edificio. Las menciones a otros espacios como iglesias, hornos, baños o puertas de la ciudad, y la alusión al barrio o la collación en la que se emplazaron permiten determinar su localización aproximada en la ciudad. Sin embargo, debemos señalar que la información proporcionada por los repartimientos a este respecto es insuficiente, dado que en muchas ocasiones aparecen como indicación las casas o propiedades de otros habitantes de las que inevitablemente no podemos conocer su ubicación, incluso en algunos casos solamente se alude al poblador al que se concedió sin proporcionar más detalles.

En cuanto a los propietarios de estas construcciones, solo hay alguna noticia de los dueños musulmanes de los fanādiq antes de la conquista en algunos alfondechs de Valencia, sin especificar su oficio. Por otra parte, de las alhóndigas de Sevilla y Murcia no hay ninguna noticia sobre sus propietarios anteriores. En cuanto a los cristianos a los que se cedieron estos edificios encontramos tanto al rey, como a la Iglesia, a cargos públicos del entorno del monarca o también a otros habitantes de la ciudad. En consecuencia, podemos concluir que los fanādiq andalusíes fueron distribuidos entre pobladores catalanes, aragoneses o castellanos de distinta condición social o bien quedaron en posesión del Rey. De estas tres urbes, solo en el caso de Sevilla se ha podido documentar a través del Repartimiento que una de estas alhóndigas fuera asignada a un grupo de comerciantes extranjeros, genoveses. Sin embargo, debemos destacar que se les otorgó con la condición de que ellos la construyeran junto con un horno y un baño. Para Constable, las alhóndigas o alfondechs reales fueron comunes en el nuevo contexto cristiano, conviviendo con otros similares de distinto propietario y los concedidos a

87 Constable, Olivia Remie, Housing the Stranger..., p. 173.

88 Ibidem, p. 174. 
grupos de comerciantes extranjeros. Además, ha propuesto que aquellos propiedad del rey se centraron en ciertos tipos de bienes para la recaudación de impuestos asociados a ellos y su almacenamiento, con el objetivo de que los beneficios económicos que produjeran fueran a parar a las arcas de la Corona ${ }^{89}$. Este sería el caso de las alhóndigas de la sal y de la harina identificadas en Murcia y Sevilla. A lo largo del siglo XIII fue algo habitual que se establecieran monopolios reales sobre ciertos productos. Sin olvidar que determinados bienes fueran gravados por parte del rey y su pago debiera realizarse en una alhóndiga en concreto, estos edificios también llevaron aparejados otro tipo de costes que estarían relacionados con su propiedad. Tal es el caso de los asientos del repartimiento de Valencia que especifican la cantidad concreta que el poblador debía rendir al rey a cambio del inmueble, por ejemplo, como censo anual.

Concluimos que los fanādiq andalusíes se distribuyeron a pobladores de distinta condición y continuaron en uso como alhóndigas o alfondechs. A partir de ese momento siguieron un desarrollo propio y particular en cada caso, según si quedaron en manos del rey o de particulares con distintos oficios o cargos de relevancia. Así hemos identificado la especialización de ciertas estructuras, como las alhóndigas de la sal en Sevilla y Murcia, o la de la harina en Sevilla. Dicha especialización no tuvo por qué ser inmediata y pudo producirse con el paso del tiempo, como ha quedado atestiguado en el caso valenciano al estipularse el traslado del almudí o la tintorería del alfondech a edificios propios en el alcázar de Valencia a finales del siglo XIII. Esto sugiere que su carácter polifuncional en los años anteriores e inmediatamente posteriores a la conquista fue cambiando, en favor de su especialización, a partir del siglo XIV. Es bien conocida la presencia de alhóndigas de cereal en distintas localidades de la Península en funcionamiento incluso en época moderna.

Además de identificar ciertos cambios, también se observan continuidades en su actividad. De hecho, las construcciones de las ciudades islámicas a menudo sirvieron para el mismo propósito bajo control cristiano que reguladas por el poder islámico (tiendas, hornos, baños, mercados, etc.). Así, no debe extrañarnos que muchos fanādiq continuaran sirviendo como hospederías, almacenes y lugares para la venta y la recaudación de impuestos. En algunos casos esta continuidad ha quedado establecida de forma específica, por ejemplo, cuando Alfonso X estableció con respecto a la alhóndiga de la harina de Sevilla que los recueros moros diesen en dicha alhóndiga del Rey el derecho que solían dar en tiempo del miramamolín ${ }^{90}$, es decir, el pago que daban al gobernante musulmán. En cuanto a los problemas o límites de esta investigación, debemos mencionar que también es habitual encontrar estos edificios en la documentación solamente relacionados con el nombre de una persona, el poblador al que se concede, sin poder conocer más detalles sobre su actividad o lo que ocurrió con ellos. No debemos descartar entonces, que muchos de ellos fueran vendidos, comprados o heredados como cualquier otra propiedad urbana por los habitantes de la ciudad. A esto se añade el hecho de que,

89 Constable, Olivia Remie, Housing the Stranger..., p. 160.
90 GonzÁlez, Julio, Repartimiento de Sevilla (I)..., p. 337. 
tras la concesión del inmueble a un poblador, no se hayan conocido más datos sobre su uso posterior. Por este motivo de algunas de estas estructuras se pierde la pista del desarrollo que pudieron tener a lo largo del tiempo, sin poder determinar tampoco si dejaron de usarse como alhóndiga o alfondech para pasar a tener una utilidad diferente. A pesar de las limitaciones expuestas sobre la información proporcionada por los libros del repartimiento, consideramos que se trata de una fuente muy importante para conocer el urbanismo andalusí, puesto que ofrece información sobre el parcelario de las ciudades en el momento inmediatamente posterior a la conquista de cada una de ellas. Por este motivo, la extensión de este tipo de estudio a otras localidades de la península Ibérica contribuirá a conocer con mayor detalle la presencia de alhóndigas y alfondech en territorio cristiano, así como su evolución y diferencias entre unos territorios y otros. Del mismo modo permitirá plantear la presencia de fanādiq en otras zonas durante el período andalusí. Además, la investigación detallada de la presencia de estos edificios en el contexto de la conquista y su cesión o donación como alhóndigas o alfondechs, pone de relevancia el papel de los fanādiq en al-Andalus y su utilidad, al ser adoptados $\mathrm{y}$ adaptados para seguir en funcionamiento en la administración concejil. 


\section{Anexo}

La ausencia de información en la documentación estudiada sobre alguno de los aspectos se indica en los campos con las siglas A. I.

Figura 1. Plano con las zonas de ubicación de alfondechs en Valencia' ${ }^{91}$ 1: Barrio de

Zaragoza; 2: Barrio de Teruel; 3: Barrio de Montpellier; 4: Arrabal Boatella; 5: Barrio de

Montblanch; 6: Barrio de Daroca; 7: Templi; 8: Arrabal próximo a bāb al-Hanaš.

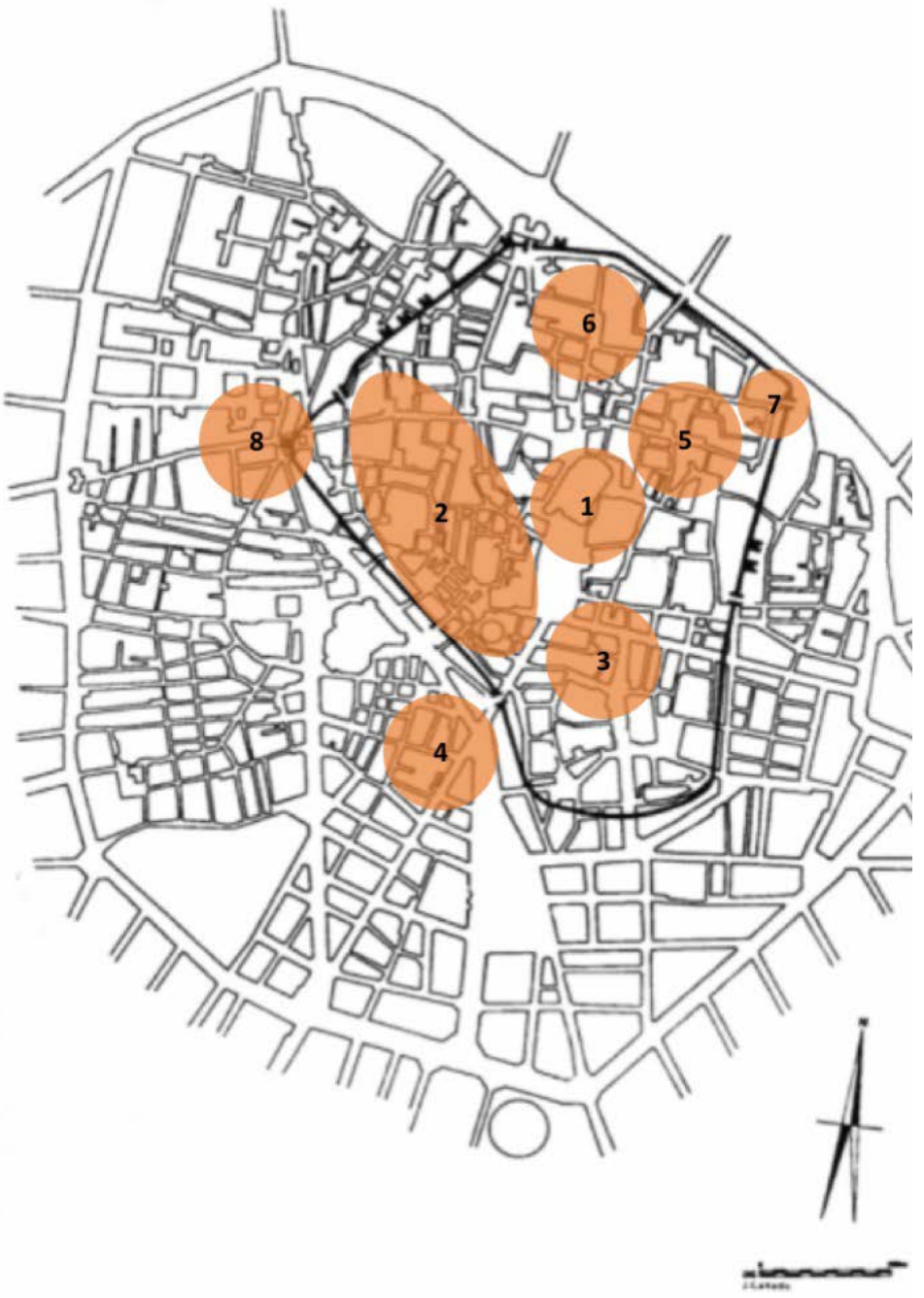

\footnotetext{
91 Plano elaborado a partir del plano de los baños árabes de la ciudad de Valencia publicado en Herreros, Tina, "Un espacio para el rito social. Los baños árabes de la calle Poeta Querol (Valencia)", Historia de la
} Ciudad. II: Territorio, sociedad y Patrimonio, Colegio Territorial de Arquitectos de Valencia, 2002, p. 83 


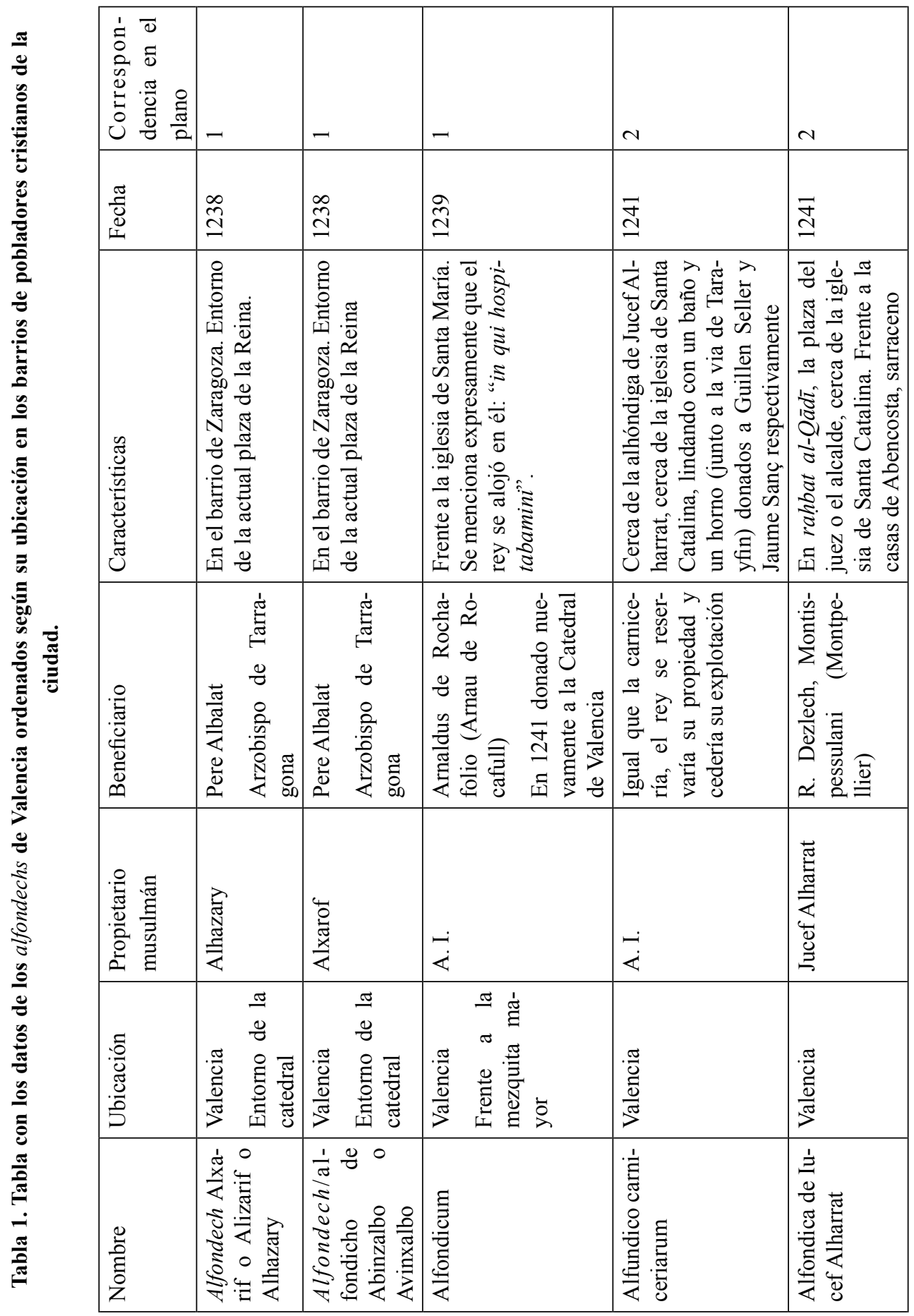


La Pervivencia del funduQ andalusí en las ciudades de Valencia, Murcia y Sevilla...

\begin{tabular}{|c|c|c|c|c|c|c|c|}
\hline$N$ & $N$ & $\sim$ & $N$ & $N$ & $N$ & $m$ & $m$ \\
\hline 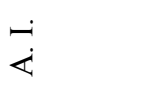 & ¿ & $\stackrel{\sim}{\check{L}}$ & $\stackrel{\sim}{\dot{\varkappa}}$ & 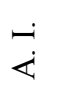 & 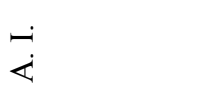 & થે & તે \\
\hline 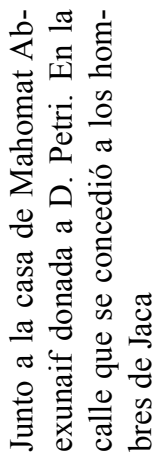 & 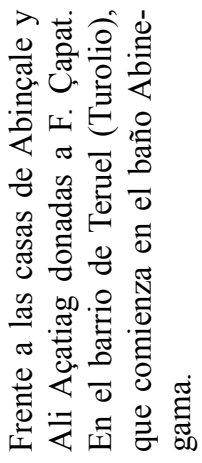 & 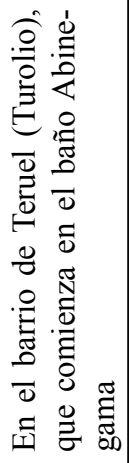 & 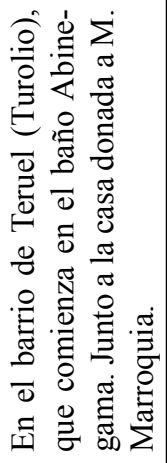 & 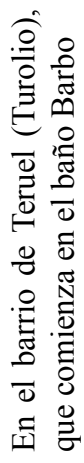 & 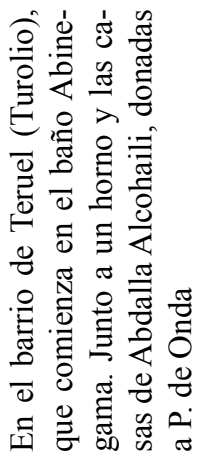 & 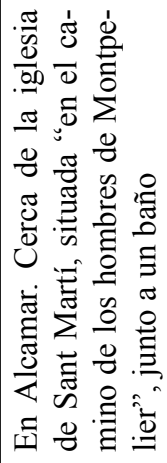 & 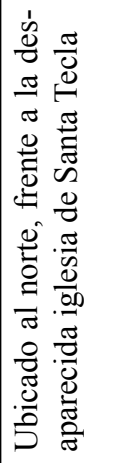 \\
\hline 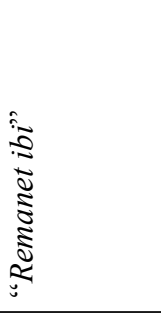 & $\stackrel{\leftarrow}{\dot{\varkappa}}$ & 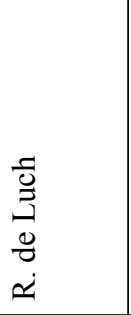 & 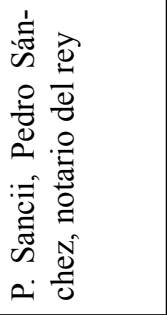 & $\begin{array}{l}\text { E. } \\
\text { W } \\
\text { م. }\end{array}$ & 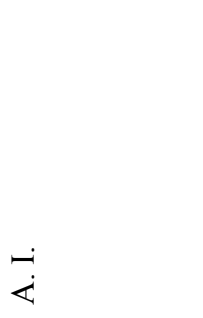 & 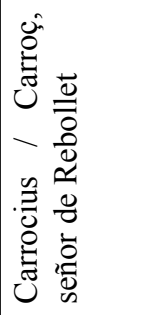 & 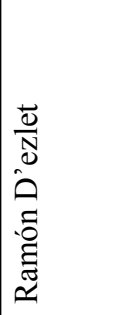 \\
\hline 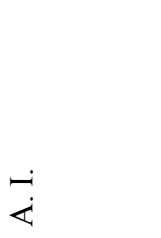 & $\ddot{\dot{\varkappa}}$ & $\stackrel{一}{\dot{\ll}}$ & $\stackrel{\dot{<}}{\ddot{<}}$ & $\stackrel{\dot{\leftrightarrow}}{\ddot{\leftrightarrow}}$ & $\stackrel{-}{\ddot{\alpha}}$ & $\stackrel{-}{\ddot{<}}$ & 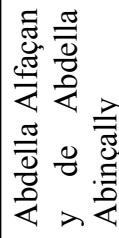 \\
\hline $\begin{array}{l}\frac{\pi}{0} \\
\frac{0}{0} \\
\frac{\pi}{\pi}\end{array}$ & $\frac{\frac{\pi}{0}}{\frac{\pi}{0}}$ & $\begin{array}{l}\frac{\pi}{\frac{\pi}{0}} \\
\frac{\overrightarrow{0}}{\pi} \\
\frac{\pi}{\nu}\end{array}$ & $\begin{array}{l}\frac{\pi}{0} \\
\frac{\overrightarrow{0}}{\pi} \\
\frac{\pi}{\nu}\end{array}$ & $\begin{array}{l}\frac{\pi}{0} \\
\frac{\pi}{\pi} \\
\frac{\pi}{j}\end{array}$ & $\frac{\frac{\pi}{0}}{\frac{\pi}{0}}$ & $\frac{\frac{\pi}{0}}{\frac{0}{0}}$ & $\begin{array}{l}\frac{\pi}{0} \\
\frac{\vec{d}}{\pi} \\
\frac{\pi}{\pi}\end{array}$ \\
\hline 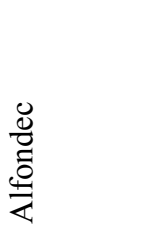 & 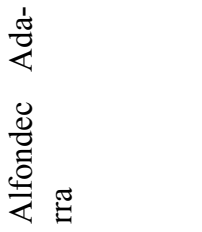 & 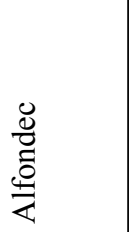 & 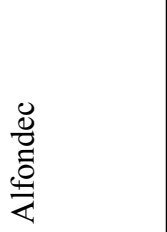 & $\begin{array}{l}0 \\
\frac{8}{0} \\
0 \\
\stackrel{0}{4} \\
\end{array}$ & 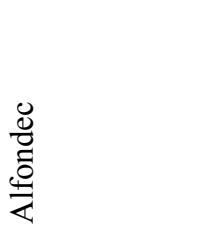 & 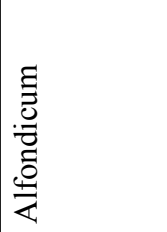 & 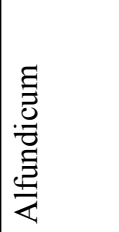 \\
\hline
\end{tabular}




\begin{tabular}{|c|c|c|c|c|c|c|c|c|}
\hline$\nabla$ & $n$ & $n$ & 6 & 6 & $r$ & $\stackrel{\dot{\varkappa}}{\dot{<}}$ & $\stackrel{\dot{\alpha}}{\dot{\alpha}}$ & $\infty$ \\
\hline ڤે & Әે & 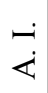 & $\stackrel{\dot{\leftrightarrow}}{\ddot{\leftrightarrow}}$ & 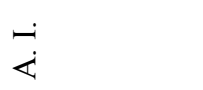 & $\stackrel{\check{\leftrightarrow}}{\ddot{\leftrightarrow}}$ & $\stackrel{\stackrel{O}{I}}{=}$ & $\underset{工}{\stackrel{J}{J}}$ & 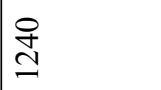 \\
\hline 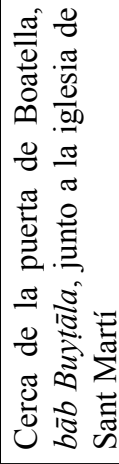 & 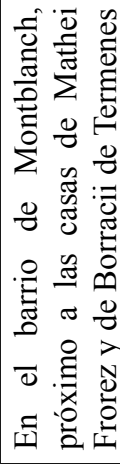 & 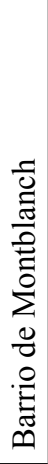 & 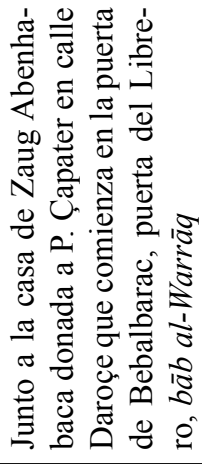 & 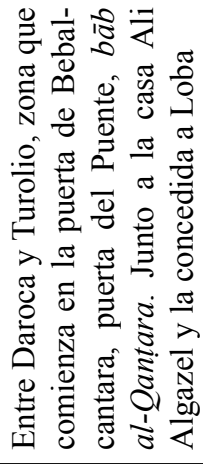 & 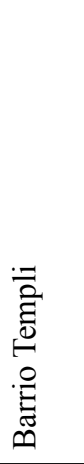 & 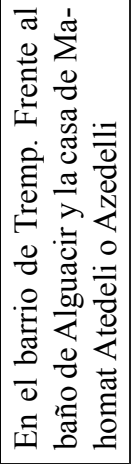 & 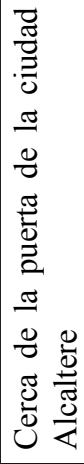 & 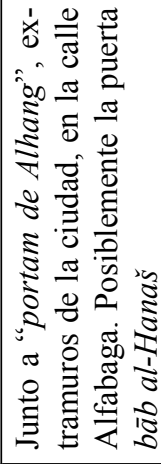 \\
\hline 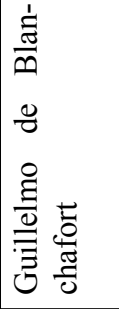 & 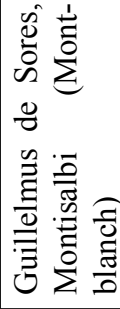 & 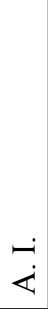 & $\stackrel{\dot{\iota}}{\sim}$ & $\stackrel{\dot{\iota}}{\dot{4}}$ & $\stackrel{\dot{\iota}}{\dot{\iota}}$ & 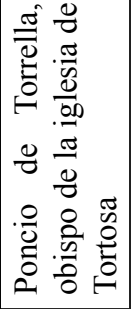 & 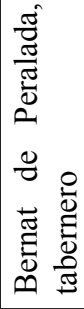 & 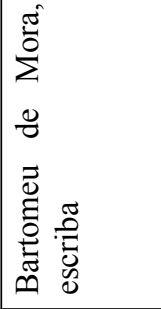 \\
\hline ¿ & $\stackrel{\text { ¿ }}{\dot{<}}$ & $\stackrel{-}{\dot{<}}$ & $\stackrel{\sim}{\dot{4}}$ & $\stackrel{\sim}{\dot{\iota}}$ & $\stackrel{\sim}{\dot{<}}$ & $\stackrel{\sim}{\dot{\varkappa}}$ & $\stackrel{\text { ¿ }}{\dot{\varkappa}}$ & 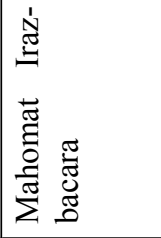 \\
\hline $\begin{array}{l}\frac{\pi}{\frac{\pi}{d}} \\
\frac{0}{\pi} \\
\frac{\pi}{j}\end{array}$ & $\begin{array}{l}\frac{\pi}{\frac{\pi}{d}} \\
\frac{\pi}{\pi} \\
\frac{\pi}{\pi}\end{array}$ & $\frac{\frac{\pi}{0}}{\frac{\pi}{0}}$ & $\frac{\frac{\pi}{0}}{\frac{\pi}{0}}$ & $\begin{array}{l}\frac{\pi}{0} \\
\frac{\pi}{0} \\
\frac{\pi}{\pi}\end{array}$ & $\frac{\frac{\pi}{0}}{\frac{\pi}{0}}$ & $\frac{\frac{\pi}{0}}{\frac{\overrightarrow{0}}{\pi}}$ & $\frac{\frac{\pi}{0}}{\frac{0}{0}}$ & 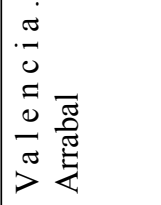 \\
\hline 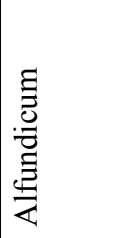 & 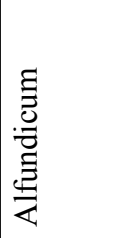 & 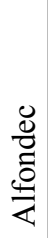 & 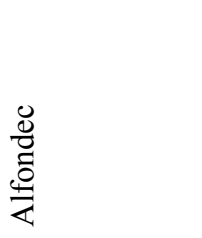 & 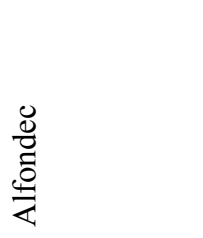 & 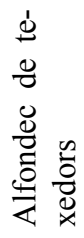 & 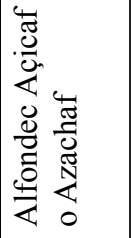 & 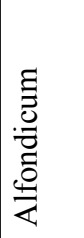 & 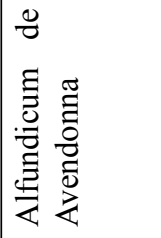 \\
\hline
\end{tabular}


La Pervivencia del funduQ andalusí en las ciudades de Valencia, Murcia y Sevilla...

\begin{tabular}{|c|c|c|c|c|c|c|c|c|c|c|}
\hline$\infty$ & $\infty$ & 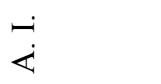 & $\stackrel{-}{\dot{\alpha}}$ & $\stackrel{\dot{\leftrightarrow}}{\dot{\leftrightarrow}}$ & $\stackrel{-}{\dot{<}}$ & $\stackrel{\dot{\leftrightarrow}}{\ddot{\leftrightarrow}}$ & $\stackrel{\dot{\leftrightarrow}}{\dot{\leftrightarrow}}$ & $\stackrel{\dot{\leftrightarrow}}{\dot{\leftrightarrow}}$ & & \\
\hline તે & શે & હે & సે & $\stackrel{\stackrel{ }{さ}}{=}$ & $\stackrel{\stackrel{ }{I}}{=}$ & શે & શે & $\stackrel{\stackrel{ }{工 ~}}{工}$ & \multirow{2}{*}{\multicolumn{2}{|c|}{ 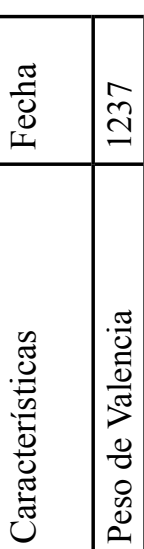 }} \\
\hline 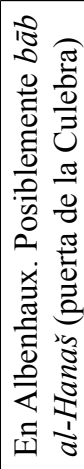 & 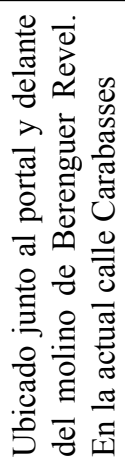 & 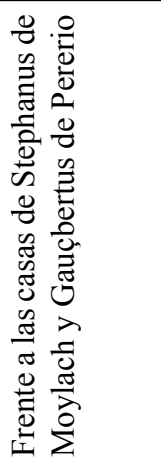 & $\stackrel{\text { ¿ }}{\dot{\alpha}}$ & 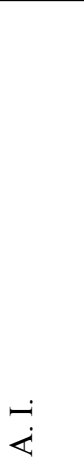 & 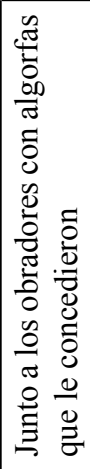 & 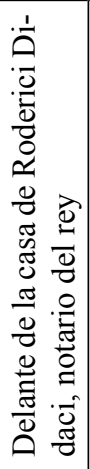 & 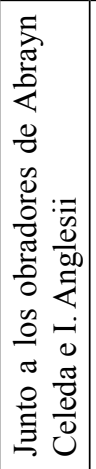 & $\stackrel{\dot{\leftrightarrow}}{\ddot{\leftrightarrow}}$ & & \\
\hline 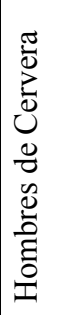 & $\begin{array}{l}\tilde{J}_{0}^{0} \\
\sum_{0}^{0} \\
0 \\
0 \\
0 \\
0 \\
0 \\
0 \\
0 \\
0 \\
0\end{array}$ & 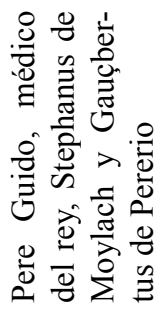 & 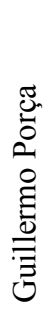 & 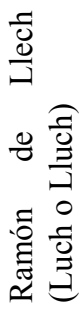 & 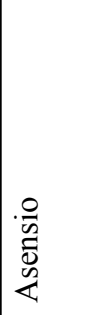 & 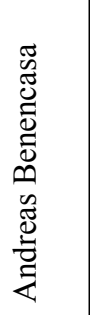 & $\stackrel{\dot{\varkappa}}{\dot{\alpha}}$ & 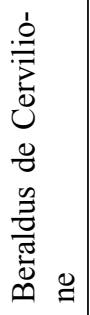 & 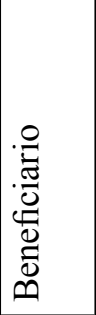 & \begin{tabular}{l}
$\frac{1}{0}$ \\
\multicolumn{2}{c}{} \\
0 \\
0 \\
0 \\
0
\end{tabular} \\
\hline 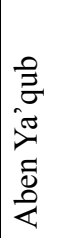 & $\stackrel{一}{\ddot{\alpha}}$ & 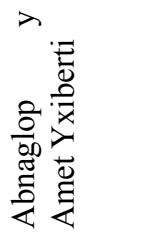 & $\stackrel{\dot{\leftrightarrow}}{\dot{\alpha}}$ & $\stackrel{\dot{\leftrightarrow}}{\dot{\leftrightarrow}}$ & $\stackrel{\dot{\leftrightarrow}}{\ddot{\alpha}}$ & $\stackrel{\dot{\leftrightarrow}}{\dot{\leftrightarrow}}$ & $\stackrel{\dot{\iota}}{\dot{\leftrightarrow}}$ & $\stackrel{-}{\dot{<}}$ & 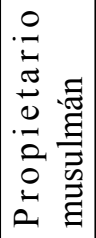 & $\stackrel{\sim}{\dot{\leftrightarrow}}$ \\
\hline $\begin{array}{l}\frac{\pi}{0} \\
0 \\
0 \\
0 \\
\frac{\pi}{\pi} \\
>\pi \\
>\end{array}$ & 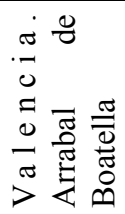 & $\begin{array}{l}\frac{\pi}{0} \\
\frac{\pi}{\pi} \\
\frac{\pi}{\pi}\end{array}$ & $\frac{\frac{\pi}{0}}{\frac{0}{\pi}}$ & $\frac{\frac{\pi}{\frac{\pi}{0}}}{\frac{0}{\pi}}$ & $\frac{\frac{\pi}{0}}{\frac{\overrightarrow{0}}{\pi}}$ & $\begin{array}{l}\frac{\pi}{0} \\
\frac{0}{\pi} \\
\frac{\pi}{\pi}\end{array}$ & $\frac{\frac{\pi}{0}}{\frac{0}{0}}$ & $\begin{array}{l}\frac{\pi}{0} \\
\frac{0}{\frac{0}{\pi}} \\
>\end{array}$ & 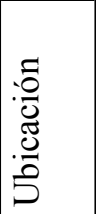 & $\stackrel{\dot{u}}{\dot{\psi}}$ \\
\hline 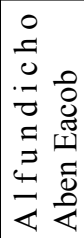 & 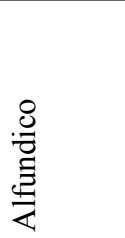 & 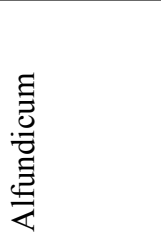 & 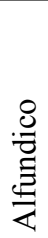 & 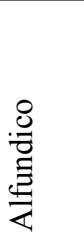 & 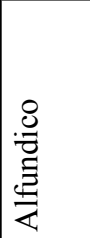 & 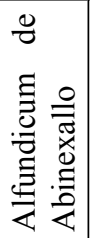 & 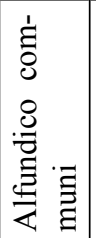 & 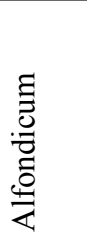 & $\begin{array}{l}\text { D. } \\
\text { है } \\
\text { ¿ }\end{array}$ & 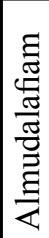 \\
\hline
\end{tabular}


Figura 2. Plano con las zonas de ubicación de alhóndigas en Murcia $^{92}$. 1: Collación de San

Pedro; 2: Arrabal de la Arrixaca (zona próxima a la calle de la Sal, actual calle Federico Balart).

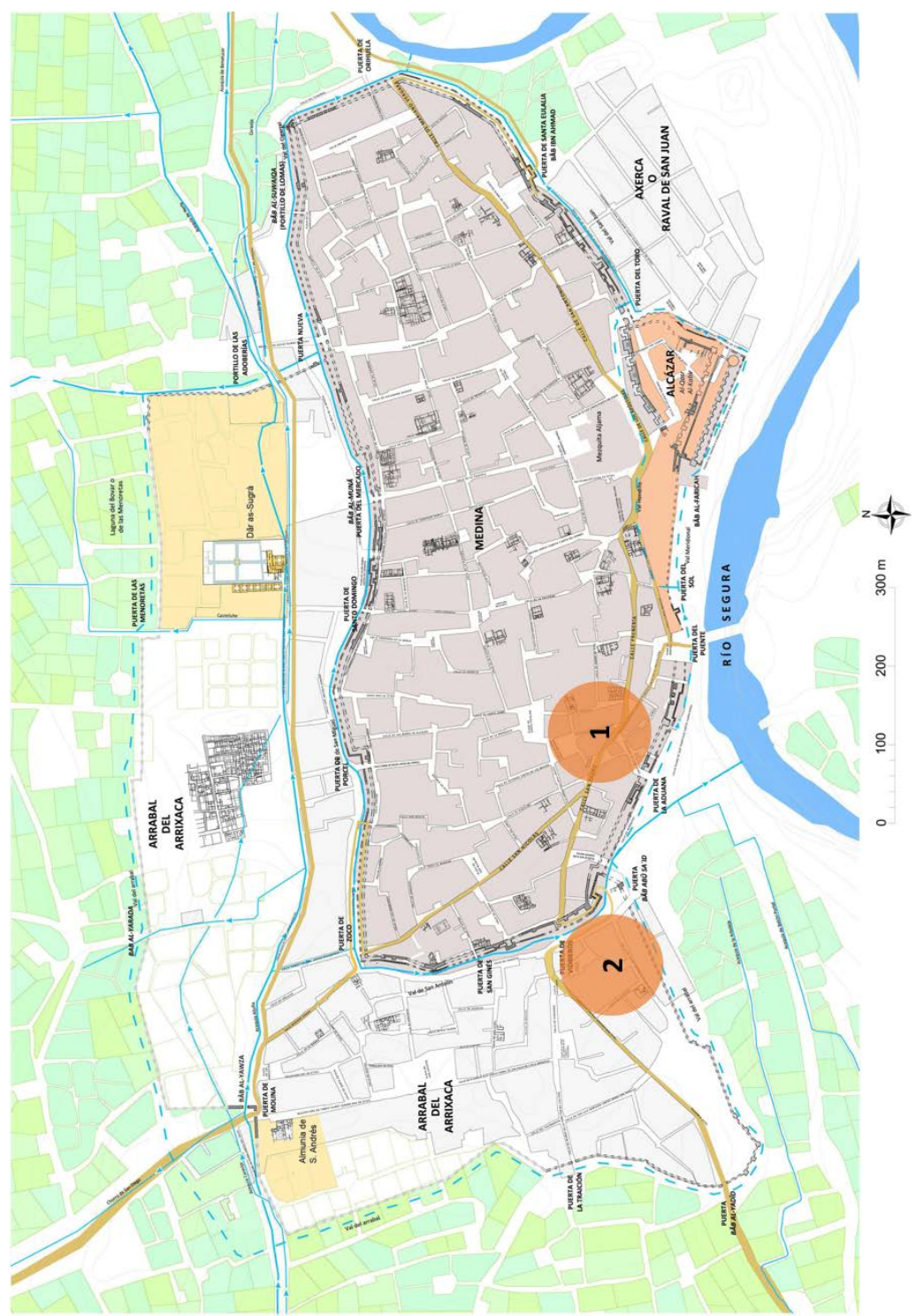

92 Plano elaborado a partir del plano general de la Murcia andalusí hacia el siglo XIII publicado en Jiménez CAstillo, Pedro, "Las murallas de la ciudad de Murcia y las fortalezas de su alfoz", Castillos de España, Monográfico de la Región de Murcia, 2021, p. 9. 


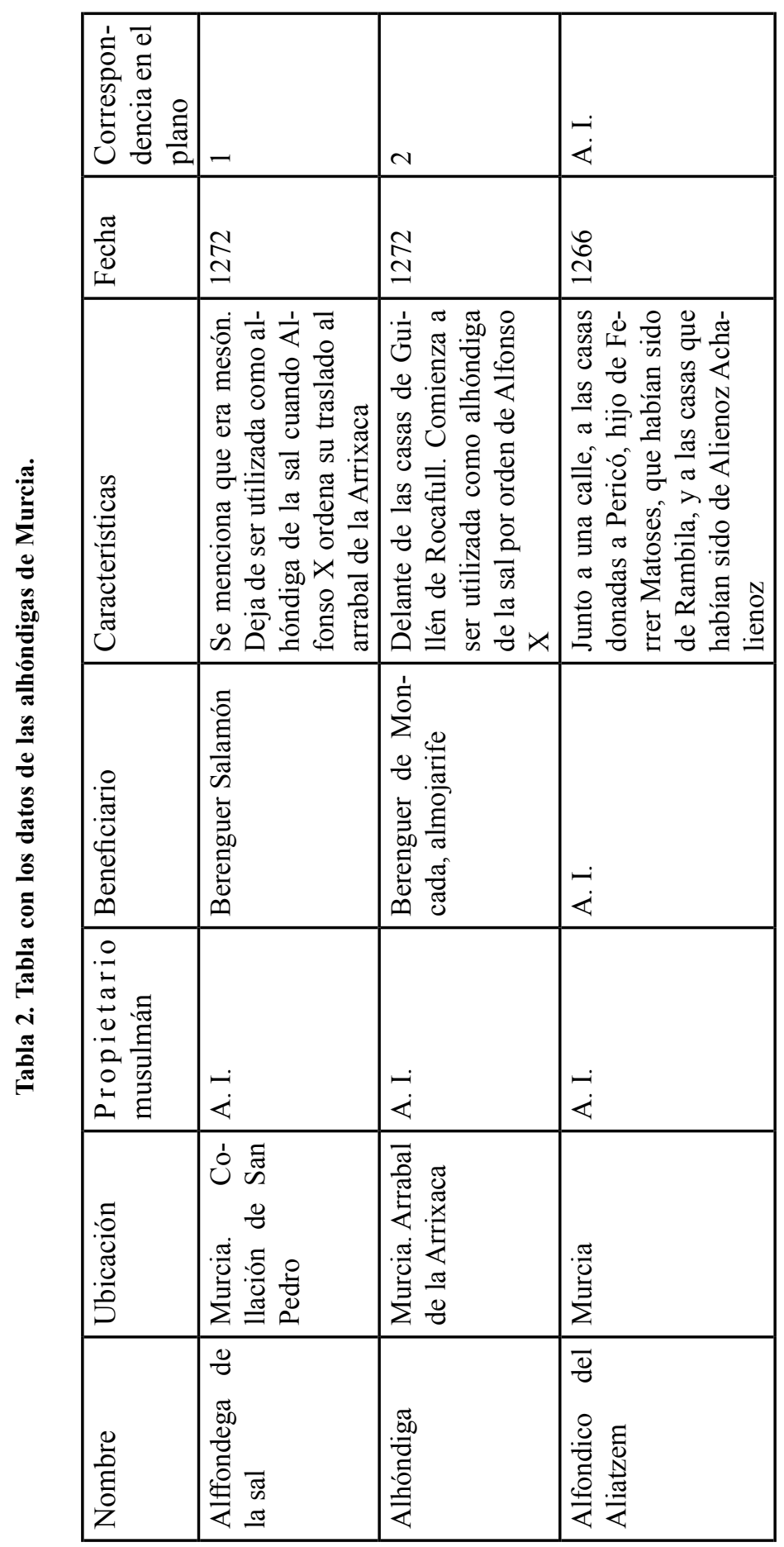


Figura 3. Plano con las zonas de ubicación de alhóndigas en Sevilla ${ }^{93}$. 1: Collación de Santa María la Mayor; 2: Collación de San Isidoro; 3: Collación de San Pedro; 4: Judería.

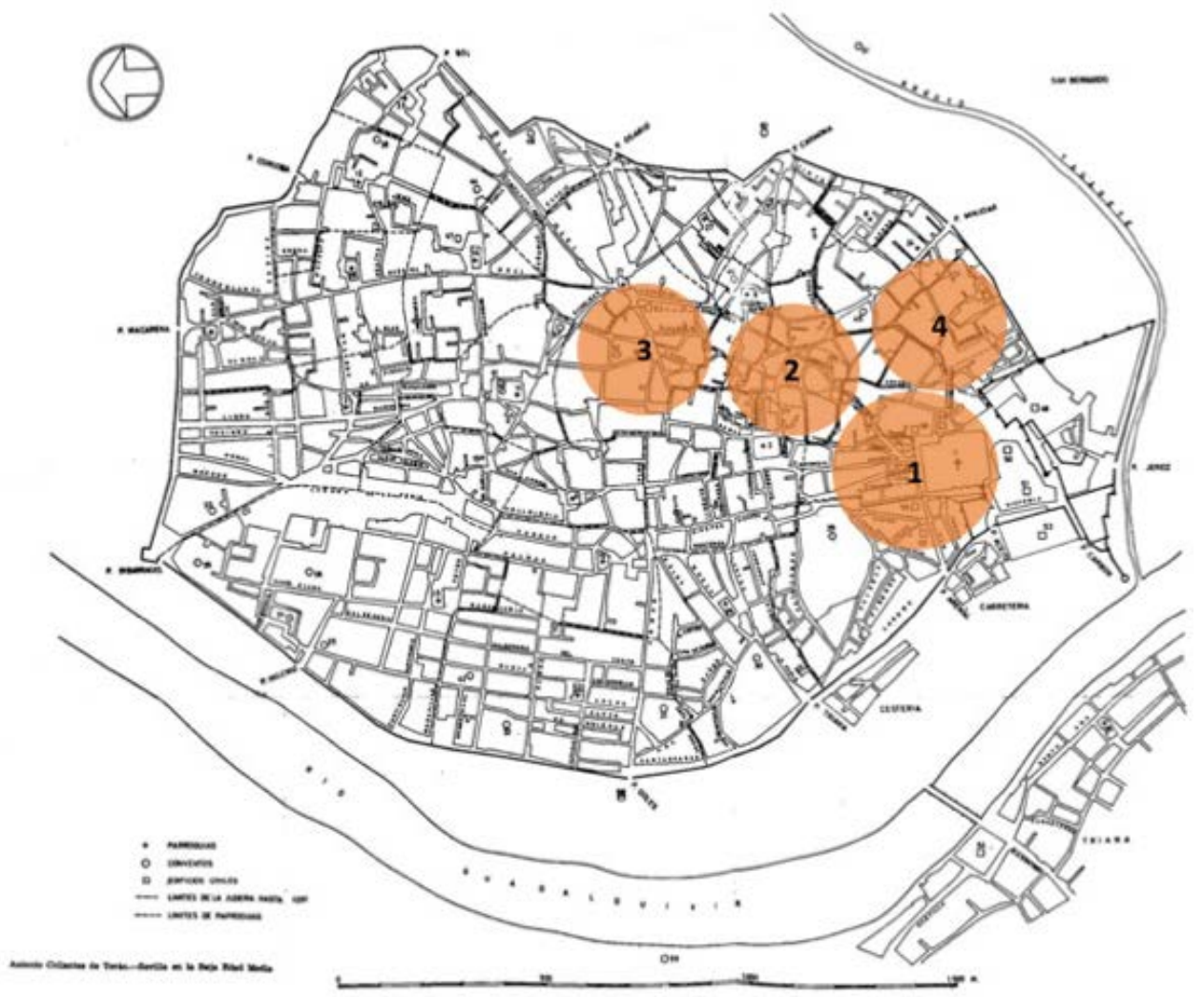

93 Plano elaborado a partir del plano de Sevilla en la Baja Edad Media publicado en Collantes de Terán SÁnchez, Antonio, Sevilla en la Baja Edad Media..., plano I. 
La Pervivencia del funduQ andalusí en las ciudades de Valencia, Murcia y Sevilla...

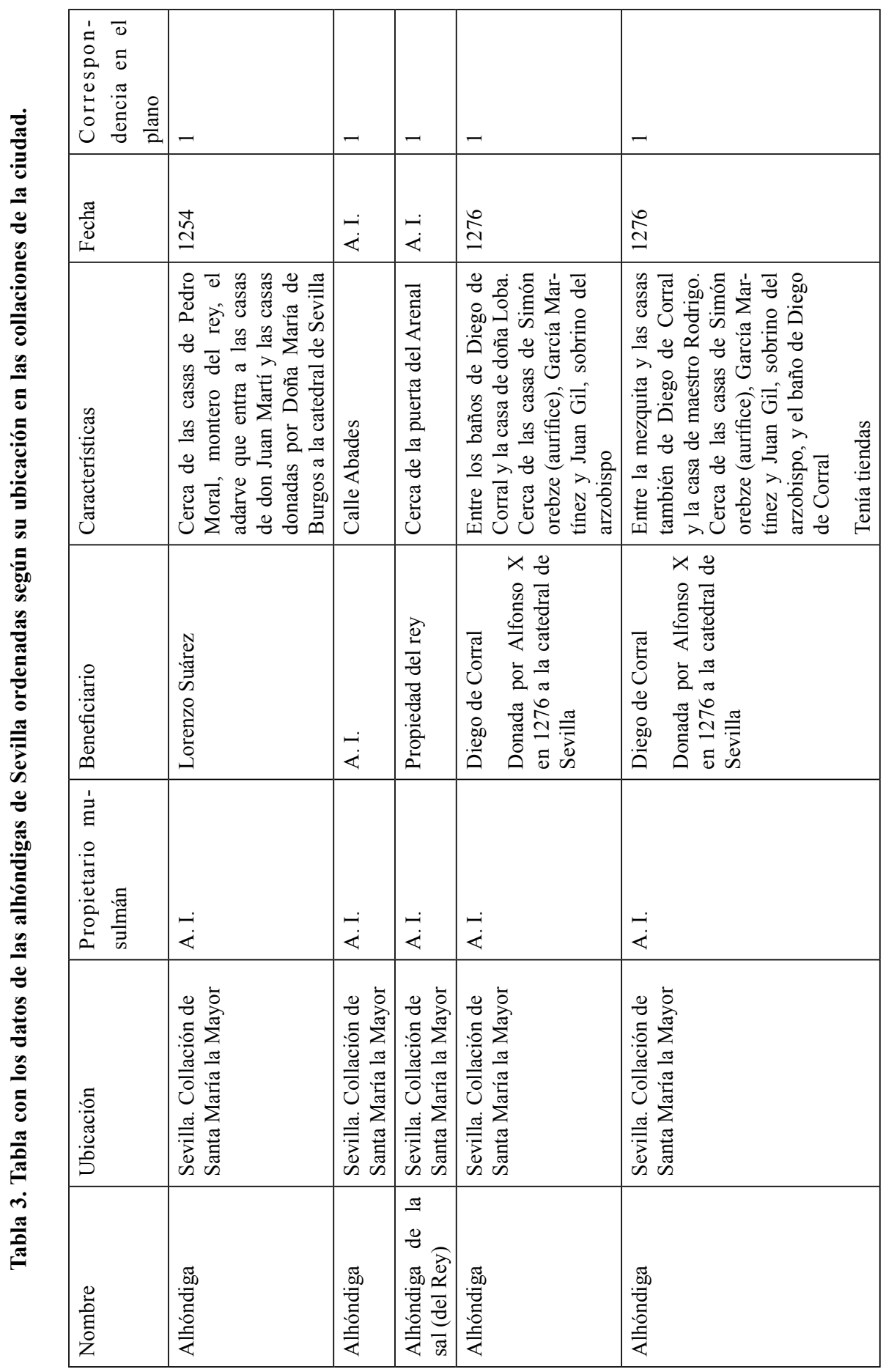




\begin{tabular}{|c|c|c|c|}
\hline$N$ & $\mathrm{~N}$ & $\mathrm{~N}$ & 4 \\
\hline$\stackrel{\check{\beth}}{\beth}$ & 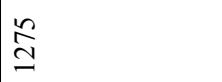 & 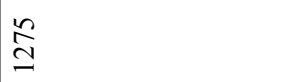 & $\begin{array}{l}\stackrel{\mathbb{U}}{\Xi} \\
=\end{array}$ \\
\hline 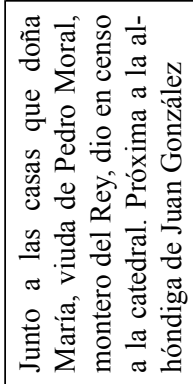 & 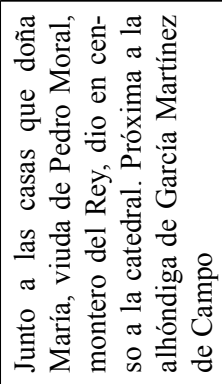 & 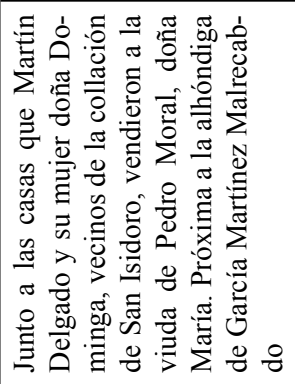 & 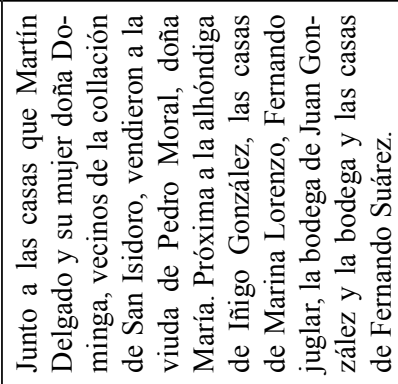 \\
\hline 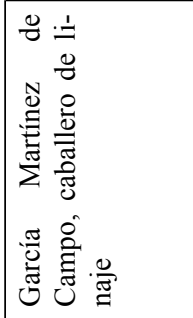 & 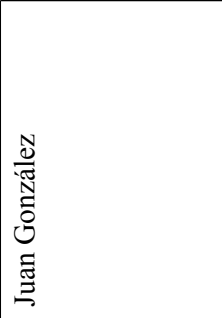 & 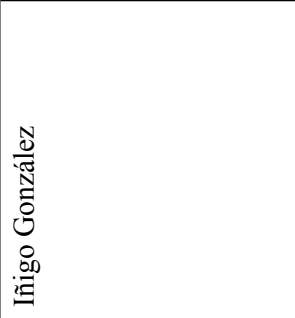 & 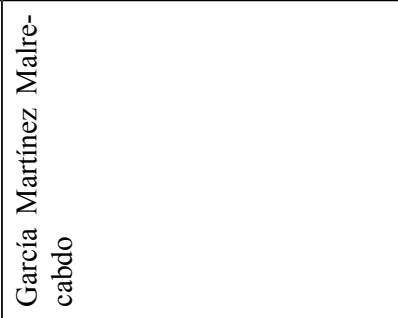 \\
\hline$\dot{\leftrightarrow}$ & $\stackrel{\dot{\leftrightarrow}}{\dot{4}}$ & $\dot{<}$ & $\stackrel{-\dot{4}}{\dot{4}}$ \\
\hline 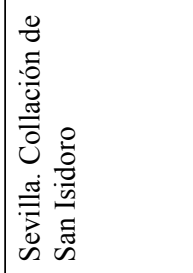 & 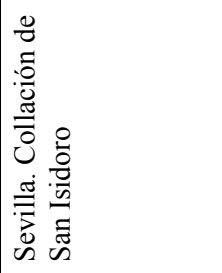 & 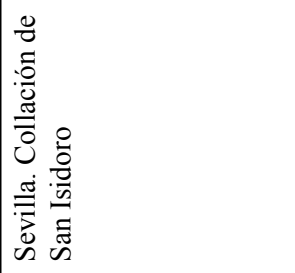 & 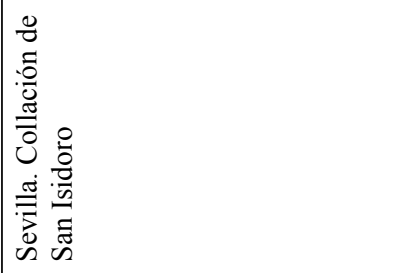 \\
\hline 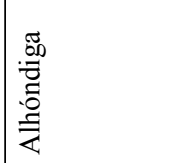 & 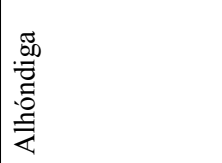 & 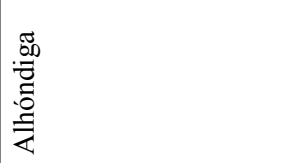 & 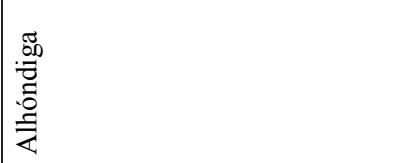 \\
\hline
\end{tabular}




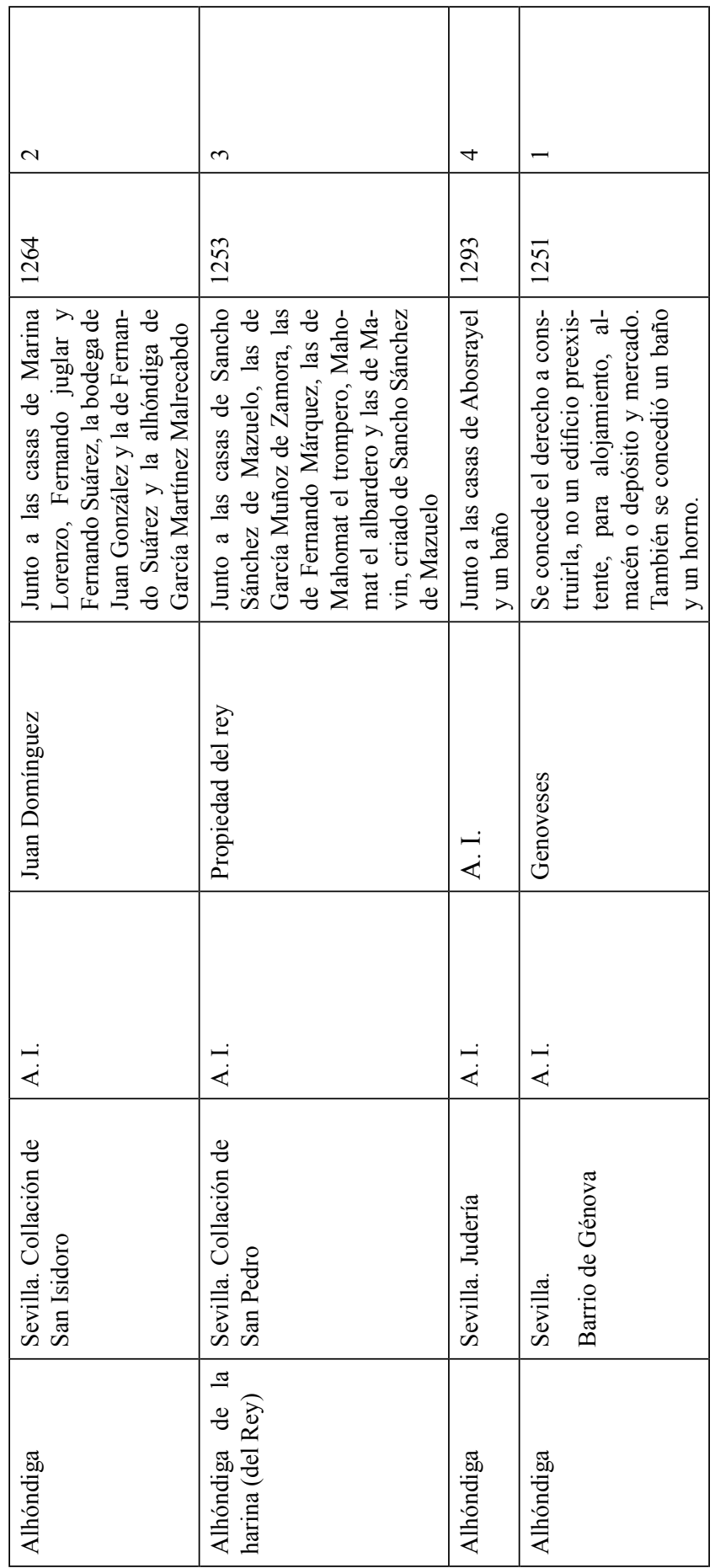




\section{Bibliografía}

Abboud Haggar, Soha, "Precedentes andalusíes en la fiscalidad de las comunidades mudéjares", En la España medieval, 31 (2008), pp. 475-512.

AL-SaqaṬi AL-MāLaqi, Kitāb fì ādāb al-hisba (Libro del buen gobierno del zoco), trad. Pedro Chalmeta y Federico Corriente, Fundación Ibn Tufayl de Estudios Árabes, Almería, 2014.

aL-SaqAṬi AL-MĀLaqI, "Kitab fi adab al-hisba (libro del buen gobierno del zoco) de alSaqati”, trad. Pedro Chalmeta, Al-Andalus, 32 (1) (1967), pp. 125-162; 32 (2) (1967), pp. 359-397; 33 (1) (1968), pp. 143-195; 33 (2) (1968), pp. 432-433.

Alcover Cateura, Pedro José, Els mercats alimentaris de la Corona d'Aragó a través de la documentació municipal (segles XIV-XV), Tesis doctoral inédita, Universidad de Barcelona, 2020.

BArceló Torres, Carmen, "Algunas notas sobre la ciudad islámica de Valencia", Homenaje a Don José María Lacarra de Miguel en su jubilación del profesorado. Estudios medievales, Anubar Ediciones, Zargoza, 1977, vol. II, pp. 175-186.

Barceló Torres, Carmen, "Valencia islámica: paisaje y espacio urbano", Historia de la Ciudad. Recorrido histórico por la arquitectura y el urbanismo de Valencia, Colegio Oficial de Arquitectos de la Comunidad Valenciana, Valencia, 2000, pp. 39-49.

BArceló Torres, Carmen, "Clave árabe para el Repartiment de Valencia”, Saitabi: revista de la Facultat de Geografia i Història, 66 (2016), pp. 11-26.

Burns, Robert Ignatius, Diplomatarium of the Crusader Kingdom of Valencia: The Registered charters of Its Conqueror Jaume I, 1257-1276 III: Documents 501-1000. Transition in Crusader Valencia: Years of Triumph, Years of War, 1264-1270, Princeton University Press, Princeton, 2001.

Burns, Robert Ignatius, "Baths and Caravanserais in Crusader Valencia", Speculum, 46(3) (1971), pp. 443-458.

Cabanes Pecourt, María Desamparados, El "repartiment” de la ciudad de Valencia, Anubar Ediciones, Zaragoza, 1977.

Cabanes Pecourt, María Desamparados, Organización autonómica del Reino de Valencia, Anubar Ediciones, Zaragoza, 1978.

Cabanes Pecourt, María Desamparados, "Escribanos y notarios en el "Repartiment" de Valencia", Anales de la universidad de Alicante, 4-5 (1986), pp. 287-304.

Cabanes Pecourt, María Desamparados, "Los primeros establecimientos comerciales de la Valencia cristiana: los obradores (siglo XIII)", El món urbà a la Corona d'Aragó del 1137 als decrets de Nova Planta, Salvador Claramunt Rodríguez (coord.), Universidad de Barcelona, Barcelona, 2003, vol. I, pp. 281-290.

Cabanes Pecourt, María Desamparados, "La repoblación de los aragoneses en Valencia", Bajar al reino: relaciones sociales, económicas y comerciales entre Aragón 
y Valencia: siglos XIII-XV, Esteban Sarasa (coord.), Institución Fernando el Católico, Zaragoza, 2017, pp. 13-30.

Cabanes Pecourt, María Desamparados y Ferrer Navarro, Ramón, Libre del Repartiment del Regne de València, Anubar Ediciones, Valencia, t. I, 1979.

Cabanes Pecourt, María Desamparados y Ferrer Navarro, Ramón, Libre del Repartiment del Regne de València, Anubar Ediciones, Valencia, t. II, 1979.

Cabanes Pecourt, María Desamparados y Ferrer Navarro, Ramón, Libre del Repartiment del Regne de València, Anubar Ediciones, Valencia, t. III, 1980.

Chalmeta Gendrón, Pedro, El «señor del zoco» en España: Edades Media y Moderna: contribución al estudio de la historia del mercado, Instituto Hispano-Árabe de Cultura, Madrid, 1973.

Chalmeta Gendrón, Pedro, El zoco medieval. Contribución al estudio de la historia del mercado. Fundación Ibn Tufayl de Estudios Árabes, Almería, 2010.

Collantes de Terán Sánchez, Antonio, Sevilla en la Baja Edad Media. La ciudad y sus hombres, Ayuntamiento de Sevilla, Sevilla, 1984.

Collantes de Terán SÁnchez, Antonio, "De la Ciudad Andalusí a la Castellana: el espacio urbano en la Andalucía Bajomedieval", Boletín de la Real academia Sevillana de Buenas Letras: Minervae Baeticae, 37 (2009), pp. 163-192.

Constable, Olivia Remie, Housing the Stranger in the Mediterranean World, Cambridge University Press, Cambridge, 2003.

ConTÉs, Josepa, Liber privilegiorum civitatis et regni Valencie. Jaume I (1236-1276), Universidad de Valencia, Valencia, 2001, t. I.

Eiroa Rodríguez, Jorge Alejandro, Haber Uriarte, María, Vallalta Martínez, Pilar, González Ballesteros, José Ángel, Hernández Robles, Alicia, Celma Martínez, Mireia, Martínez Rodríguez, Antonio Luis, Muñoz Espinosa, María Ángeles, Salas Rocamora, Sergio y Molina Campuzano, María Isabel, "El conjunto arqueológico de San Esteban: aportaciones desde la investigación interdisciplinar", XXV Jornadas de Patrimonio Cultural de la Región de Murcia, Tres Fronteras Ediciones, Murcia, 2019, pp. 41-51.

GonzÁlez, Julio, Repartimiento de Sevilla (I), Consejo Superior de Investigaciones Científicas, Madrid, 1951.

GonzÁlez, Julio, Repartimiento de Sevilla (II), Consejo Superior de Investigaciones Científicas, Madrid, 1951.

GonZÁLeZ JimÉneZ, Manuel, "Repartimientos andaluces del siglo XIII, perspectiva de conjunto y problemas", Historia. Instituciones. Documentos, 14 (1987), pp. 103-121.

GuINOT, Enric, "El repartiment feudal de l'horta de València al segle XIII: jerarquització social i reordenació del paisatge rural", Repartiments medievals a la Corona d'Aragó (segles XII-XIII), Enric Guinot y Josep Torró (eds.), Universidad de Valencia, Valencia, 2007, pp. 115-200. 
GuINOT, Enric y ToRró, Josep, "Introducció: Retorn als repartiments", Repartiments medievals a la Corona d'Aragó (segles XII-XIII), Repartiments medievals a la Corona d'Aragó (segles XII-XIII), Enric Guinot y Josep Torró (eds.), Universidad de Valencia, Valencia, 2007, pp. 9-16.

Hernández Robles, Alicia, "Comercio y alojamiento en madinat Mursiya. Estudio arqueológico de los fanādiq andalusíes en Murcia”, Arqueología y Territorio Medieval, 28 (2021), e6186.

Herreros, Tina, "Un espacio para el rito social. Los baños árabes de la calle Poeta Querol (Valencia)", Historia de la Ciudad. II: Territorio, sociedad y Patrimonio, Colegio Territorial de Arquitectos de Valencia, 2002, pp. 75-90.

Hinojosa Montalvo, José, Diccionario de historia medieval del Reino de Valencia, Biblioteca valenciana, Valencia, t. I, 2002.

Hinojosa Montalvo, José, Diccionario de historia medieval del Reino de Valencia, Biblioteca valenciana, Valencia, t. III, 2002.

Huici Miranda, Ambrosio, y Cabanes Pecourt, María Desamparados, Documentos de Jaime I de Aragón, vol. II (1237-1250), Editorial Anubar, Zaragoza, 1976.

Huici Miranda, Ambrosio, y Cabanes Pecourt, María Desamparados, Documentos de Jaime I de Aragón, vol. IV (1258-1262), Editorial Anubar, Zaragoza, 1982.

IBN 'ABD AL-RA'ŪF, Córdoba a mediados del siglo $X$, ed. y trad. Pedro Chalmeta, Fundación Ibn Tufayl de Estudios Árabes, Almería, 2019.

JimÉnez Castillo, Pedro, Murcia. De la Antigüedad al Islam, Tesis doctoral, Universidad de Granada, 2013.

Jiménez CAstillo, Pedro, "Las murallas de la ciudad de Murcia y las fortalezas de su alfoz”, Castillos de España, Monográfico de la Región de Murcia, 2021, pp. 5-38.

Jiménez Castillo, Pedro, y Navarro Palazón, Julio, "El urbanismo islámico y su transformación después de la conquista cristiana: el caso de Murcia", La ciudad medieval: de la casa al tejido urbano, Jean Passini (coord.), Universidad de Castilla-La Mancha, Toledo, 2001, pp. 71-130.

JiMÉNEz RoLDÁN, María del Carmen, "Del funduq a la alhóndiga: un espacio entre el emirato nazarí y el reino de Granada (s. XV-XVI)”, Al-Qantara, 40-2 (2019), pp. 315-354. LAdero QuesadA, Miguel Ángel, "Las ciudades de Andalucía occidental en la Baja Edad Media. Sociedad, morfología y funciones urbanas”, En la España Medieval, 10 (1987), pp. 69-108.

Laliena Corbera, Carlos, "Repartos de tierras en el transcurso de la conquista feudal del valle del Ebro (1080-1160)", Repartiments medievals a la Corona d'Aragó (segles XII-XIII), Enric Guinot y Josep Torró (eds.), Universidad de Valencia, Valencia, 2007, pp. 17-50.

LÉvi-Provençal, Évariste y García Gómez, Emilio, Sevilla a comienzos del siglo XII. El tratado de Ibn 'Abdun, Biblioteca de temas sevillanos, Sevilla, 1981. 
Martí Oltra, Javier, y Burriel Alberich Josep, "Comerciar en tierra extraña. La alhóndiga musulmana de la calle Corretgeria de Valencia", Historia de la ciudad $V$. Tradición y progreso, Colegio Oficial de Arquitectos de la Comunidad Valenciana, Colegio Territorial de Arquitectos de Valencia, Valencia, 2008, pp. 41-60.

Molina Molina, Ángel Luis, Urbanismo medieval. La Región de Murcia, Universidad de Murcia, Murcia, 1992.

Navarro Palazón, Julio y Jiménez Castillo, Pedro, "Una nueva propuesta de investigación y gestión de yacimientos urbanos: la ciudad de Murcia”, Paisajes rurales y paisajes urbanos: métodos de análisis en historia medieval, Universidad de Zaragoza, Zaragoza, 1994, pp. 157-203.

Navarro Palazón, Julio y Jiménez Castillo, Pedro, “Casas y tiendas en la Murcia andalusí. Excavación en el solar municipal de la Plaza de Belluga", Memorias de Arqueología (1995), 10 (2002), pp. 490-532.

Ortega Pagán, Nicolás, Callejero murciano, Ayuntamiento de Murcia, Murcia, 1973.

Serra Defilis, Amadeo, "Nuevamente cristiana, bella y atractiva. La ciudad de Valencia entre los siglos XIII al XV", Historia de la Ciudad. Recorrido histórico por la arquitectura y el urbanismo de Valencia, Colegio Oficial de Arquitectos de la Comunidad Valenciana, Valencia, 2000, pp. 64-75.

Ruiz PARra, Inmaculada, "Excavaciones arqueológicas en el solar de la C/ Conde Valle de San Juan, esquina C/ Pascual de Murcia", Memorias de Arqueología (1990), 5 (1996), pp. 415-426.

Torres BALBÁs, Leopoldo, “Las alhóndigas hispano-musulmanas y el corral del carbón de Granada”, Al-Andalus, 11 (1946), pp. 446-480.

Torres Fontes, Juan, Repartimiento de Murcia, Escuela de Estudios Medievales. Real Academia Alfonso X el Sabio de Murcia, Murcia, 1960.

Torres Fontes, Juan, Documentos de Alfonso X el Sabio, CODOM I, Real Academia Alfonso X el Sabio de Murcia, Murcia, 1963.

Torres Fontes, J., Documentos del siglo XIII, CODOM II, Real Academia Alfonso X el Sabio, Murcia, 1969.

Torró, Josep, y Guinot, Enric, "De la Madîna a la ciutat: les pobles del sud i la urbanització dels extramurs de València (1270-1370)", Saitabi: revista de la Facultat de Geografia i Història, 51-52 (2001-2002), pp. 51-103.

YAHYÀ IBN 'Umar, Ahkam al-suq, “Unas 'ordenanzas del zoco' del siglo IX. Traducción del más antiguo antecedente de los tratados andaluces de 'hisba' por un autor andaluz", trad. Emilio García Gómez, Al-Andalus, 22 (2) (1957), pp. 253-316. 